\title{
Adolescents' access to emergency contraception in Africa: An empty promise?
}

\author{
Oluremi A Savage-Oyekunle* \\ Lecturer, Lagos State University, Lagos, Nigeria
}

\author{
Annelize Nienaber** \\ Professor of Law, Department of Public Law, University of Pretoria, South Africa
}

\section{Summary}

Governments have committed themselves at international human rights fora to prioritising programmes aimed at adolescents' development and wellbeing, particularly their educational and health needs. Such programmes include those focused on adolescents' sexual and reproductive health, and are aimed at enabling adolescents to manage in a positive manner their awakening sexuality. African countries, too, have focused their efforts on adolescents. Despite commitment by governments, an alarmingly high rate of unintended pregnancies among Africa's adolescents persists. These unintended pregnancies are associated with a low level of contraceptive use, especially among adolescent girls who face significant discrimination and inequality when accessing contraceptive information and services, including specific information on where and how to access emergency contraceptives. This situation flies in the face of the realisation that unconditional and unhindered access to emergency contraceptives is an important tool to protect adolescent girls from sexual ill-health and maternal mortality and morbidity. In light of obstacles in the way of adolescent girls' access to emergency contraception in the African region, the comments of the various treaty-monitoring bodies are highlighted in the article in order to strengthen arguments in support of African adolescents' access to emergency contraception. Additionally, mechanisms which may be adopted to overcome obstacles that hinder adolescents' access and use of emergency contraceptives are examined in

\footnotetext{
* LLB LLM (Lagos State) LLD (Pretoria); oluremi.savage-oyekunle@lasu.edu.ng

** BHons (Wits) LLB LLM LLD (Pretoria); annelize.nienaber@up.ac.za
} 
order to determine whether they may be beneficial in ensuring African adolescents' access to emergency contraception. Although the study is comparative in nature, specific attention is paid to Nigerian adolescents' access to emergency contraception.

Key words: sexual and reproductive health; adolescents; access to emergency contraception; maternal mortality

\section{Introduction}

Governments the world over increasingly realise the necessity of paying attention to the rights and needs of adolescents. Consequently, they have committed themselves at international human rights fora to prioritising programmes aimed at adolescents' development and wellbeing, particularly their educational and health needs. ' Such programmes include those focused on adolescents' sexual and reproductive health, ${ }^{2}$ and are aimed at enabling adolescents to manage in a positive manner their awakening sexuality. African countries, too, have focused their efforts on adolescents and, consequently, various African regional human rights instruments 3 emphasise the right of adolescents to access sexual health care information and services, including those relating to emergency contraception.

1 At the International Conference on Population and Development held in Cairo, Egypt, in 1994, states committed themselves to ensuring a shift away from the narrow focus on population and fertility reduction, to a broader agenda that addressed a range of $\mathrm{SRH}$ issues that affect the lives of women. In relation to adolescents, states in paras 7.44 and 7.46 of the Programme of Action committed themselves to comprehensively addressing adolescents' SRH issues, including reducing unsafe abortions, substantially reducing unwanted pregnancies, and promoting their rights to reproductive health education, information and care. In this regard, see ICPD Programme of Action, 1994, https://www.unfpa.org/sites/ default/files/event-pdf/PoA_en.pdf (accessed 9 June 2016).

2 The term SRH, though used as a combination, consists of distinct concepts. The initial definition of reproductive health in the ICPD Programme of Action and the Beijing Declaration lumped sexual health in the definition for reproductive health in para 7.2 (ICPD Programme of Action 1994 and para 94 Beijing Declaration and the Platform for Action 1995). This was done as a result of the overlapping nature of the two concepts which entail supporting normal biological functions associated with pregnancy and childbirth and reducing the adverse outcomes associated with the occurrence of sexual activities. The difference between the concepts is further highlighted by the fact that not all sexual activities result in childbirth or procreation. In a recent WHO definition of sexual health, it was noted that the sexual rights of all individuals must be respected, protected and satisfied. See WHO Measuring sexual health: Conceptual and practical considerations and related indicators (2010) 10, http://whqlibdoc.who.int/hq/2010/who_ rhr_10.12_eng.pdf (accessed 20 April 2016); AM Miller 'Sexual but not reproductive: Exploring the junction and disjunction of sexual and reproductive rights' (2000) 4 Health and Human Rights 68-109.

3 Regional human rights instruments, such as the African Charter (art 16), the African Children's Charter (art 14) and the African Women's Protocol (art 14), guarantee the right of adolescents to health care. Particularly, the African Women's Protocol recognises the right of women and adolescent girls not only to 
Adolescents in sub-Saharan Africa face numerous sexual and reproductive health hazards, including unintended pregnancies; unsafe abortions; and sexually-transmitted infections (STIs) ${ }^{4}$ as a result of their involvement in early - and often unprotected - sexual activity. $^{5}$ In addition, approximately 40 per cent of all pregnancies worldwide are unintended, with higher unintended pregnancy rates in African countries. ${ }^{6}$ In a review of the sexual and reproductive health and rights of adolescents in nine countries in sub-Saharan Africa, ${ }^{7}$ it was noted that adolescents in the region are particularly vulnerable to sexual and reproductive health issues such as high adolescent birth rates. ${ }^{8}$ According to the review, sub-Saharan Africa contributes over 50 per cent of the global adolescent birth rate, as well as over 23 per cent of the burden of diseases associated with pregnancy and child and maternal ill-health. ${ }^{9}$ Consequently, these adolescents' education and livelihood options are negatively affected. ${ }^{10}$ Unintended pregnancies among adolescents, therefore, represent a major health challenge in many African countries.

The high level of unintended pregnancies in Africa is associated with a low level of contraceptive use in the region, especially among adolescent girls who not only face significant discrimination and inequality when accessing contraceptive information and services, including particular information on where and how to access

choose appropriate methods of contraception to control their fertility, but also to ensure their self-protection against STIs and HIV and have access to family planning education; see generally arts $14(1)(a)(c)(d)$ and (g) of the African Women's Protocol. See OA Savage-Oyekunle \& A Nienaber 'Adolescent girls' access to contraceptive information and services: An analysis of legislation and policies, and their realisation, in Nigeria and South Africa' (2015) 15 African Human Rights Law Journal 433-448.

4 Globally, figures indicate that adolescents in sub-Saharan Africa remain most affected by the HIV epidemic, despite encouraging indications that the HIV prevalence is declining among young people in the region. See UNESCO Young people today: Time to act now - Why adolescents and young people need comprehensive sexuality education and sexual and reproductive health services in Eastern and Southern Africa (2013) 8, http://unesdoc.unesco.org/images/0022/ 002234/223447E.pdf (accessed 8 June 2016).

$5 \mathrm{~N}$ Lukale Adolescent reproductive health concerns in sub-Saharan Africa (2015), https://girlsglobe.org/2015/12/15/adolescent-reproductive-health-concerns-insub-saharan-africa/ (accessed 14 June 2016); CW Kabiru et al 'The health and wellbeing of young people in sub-Saharan Africa: An under-researched area?' (2013) 13 BMC International Health and Human Rights, http://bmcin thealthhumrights.biomedcentral.com/articles/10.1186/1472-698X-13-11 (accessed 15 June 2016).

6 UNFPA Adolescent pregnancy: A review of the evidence (2013) 14-15, https://www. unfpa.org/sites/default/files/pub-pdf/ADOLESCENT\%20PREGNANCY_UNFPA.pdf (accessed 14 June 2016).

7 The countries under review were Angola, Benin, Ethiopia, Rwanda, Kenya, Nigeria, Sierra Leone, Tanzania and Zambia.

8 UNFPA (n 6 above).

9 As above.

10 See OA Savage-Oyekunle 'Female adolescents' reproductive health rights: Access to contraceptive information and services in Nigeria and South Africa' LLD thesis, University of Pretoria, 2014; and World YWCA Sexual reproductive health and rights for adolescents in sub-Saharan Africa - Youth fact sheet (2014) 3. 
emergency contraceptives, ${ }^{11}$ but who also frequently are victims of sexual assault and violence. ${ }^{12}$

The poor sexual health outcomes associated with adolescence in sub-Saharan Africa are discouraging as, in theory, adolescents are 'protected' and guaranteed access to contraceptive information and services, including emergency contraceptives. ${ }^{13}$ While emergency contraception does not protect against STIs, unhindered access to it is an important tool in the prevention of unintended pregnancies among adolescents - especially pregnancies resulting from sexual violence - and consequently lends protection against sexual ill-health and maternal mortality. ${ }^{14}$

In relation to emergency contraception, specifically, Williams reports that the dearth of knowledge about relevant sexual and reproductive health care services by women and adolescent girls in sub-Saharan Africa indisputably hinders the demand for emergency contraception as women's awareness of this contraception continues to be below 10 per cent in Senegal and Zambia. ${ }^{15}$ According to Williams, even in countries such as Kenya, where reports reveal high levels of awareness of the method, the actual use of emergency contraception remains low. ${ }^{16}$

Because of these alarming statistics, African governments have resolved to integrate emergency contraception into their family planning service delivery policies and guidelines, ${ }^{17}$ and many governments offer the contraceptive method in public sector services. ${ }^{18}$ Further, adolescents' access to emergency contraception is

11 C Mouli et al 'Contraception for adolescents in low and middle-income countries: Needs, barriers, and access' (2014) 11 Reproductive Health 3-4, http:// www.reproductive-health-journal.com/content/11/1/1 (accessed 10 June 2016).

12 UNAIDS Empower young women and adolescent girls: Fast-tracking the end of the aids epidemic in Africa (2015) 12-13, http://www.unaids.org/sites/default/ files/media_asset/JC2746_en.pdf (accessed 14 June 2016); WHO World report on violence and health (2012) 152-154, http://www.who.int/violence_injury_ prevention/violence/world_report/en/full_en.pdf?ua=1 (accessed 14 June 2016).

13 See Savage-Oyekunle (n 10 above) 22-72. See also OA Savage-Oyekunle \& A Nienaber 'Female adolescents' evolving capacities in relation to their right to access contraceptive information and services: A comparative study of South Africa and Nigeria' (2015) 48 Comparative and International Law Journal of South Africa 1.

14 Wikipedia Emergency contraception, https://en.wikipedia.org/wiki/Emergency_ contraception\# History (accessed 18 June 2016).

$15 \mathrm{~K}$ Williams Provider-related barriers to accessing emergency contraception in developing countries: A literature review (2011) http://www.popcouncil.org/ uploads/pdfs/2011RH_ECBarriersLitReview.pdf (accessed 14 June 2016).

$16 \mathrm{Eg}$, in Kenya, even though $40 \%$ of the population is aware of EC, only $2 \%$ of women report ever having used it. See Williams (n 15 above).

17 In response to the state of SRH rights in the region, African governments as well as regional groups (including the African Union and SADC) developed a policy known as the Maputo Plan of Action that would be used for the achievement of $\mathrm{SRH}$ rights in the region. The Maputo Plan of Action, which was specifically broad and flexible to adapt to the unique circumstances of each country, generally contains steps that were to be adopted in order to realise universal access to SRH rights in Africa by 2015. With the passing of the 2015 deadline, a comprehensive 
premised on the obligation of state parties to human rights instruments to guarantee to adolescent girls the right to enjoy the highest attainable standard of health through their access to sexual health care services and information and, indeed, their right to choose their preferred method of contraception. ${ }^{19}$ Also based on the provisions of human rights instruments, African governments are compelled to ensure that emergency contraceptives not only are accessible, but that they are affordable and readily available to adolescents.

Despite these guarantees in human rights instruments, 20 emergency contraception remains largely inaccessible. In light of this, the article analyses obstacles in the way of adolescent girls' access to emergency contraception in sub-Saharan Africa, specifically focusing on the access to emergency contraception of adolescent girls in Nigeria. Selected comments by treaty-monitoring bodies, including those of the African Committee of Experts on the Rights and Welfare of the Child (African Children's Committee), are analysed in order to support arguments for African adolescents' access to emergency contraception in the promotion of their rights to sexual and reproductive health care. In addition, methods that may be adopted in overcoming obstacles to the use of emergency contraceptives are examined in order to determine whether they may be helpful in ensuring adolescents' access to emergency contraception on the African continent.

Below we begin with a description of emergency contraceptives and their use.

review of the implementation, achievements, challenges and gaps of the Maputo Plan of Action was carried out. This review culminated in the adoption of the revised Maputo Plan of Action 2016-2030. Para 18(vi) of the revised Maputo Plan of Action commits states to investing in the SRH needs of adolescents and other vulnerable and marginalised populations. See Maputo Plan of Action 2016-2030 for the operationalisation of the continental policy framework for sexual and reproductive health and rights, http://www.au.int/en/sites/default/files/ documents/24099-poa_5-_revised_clean.pdf (accessed 15 June 2016). See further African Union Commission's Decision on the Continental Policy Framework for the Promotion of Sexual and Reproductive Health and Rights in Africa (Doc EX.CL/225 (VIII) http://pages.au.int/sites/default/files/SRHR\%20English_0.pdf (accessed 10 September 2017). This framework was put into operation by the AU's Maputo Plan of Action on Sexual and Reproductive Health and Rights (see above).

$18 \mathrm{Z}$ Shewamene et al 'Is emergency contraceptive accessibility a barrier in developing countries? A review' (2013) 4 International Journal of Pharmaceutical Sciences and Research 1324-1325; CRR Governments Worldwide Put Emergency Contraception into Women's Hands: A global review of laws and policies (2004) 5-6, http://www.reproductiverights.org/sites/default/files/documents/pub_bp_ govtswwec.pdf (accessed 15 June 2016).

19 Art 14(1)(c) African Women's Protocol.

20 These guarantees are not discussed in detailed here. For a detailed discussion of human rights guarantees of adolescent girls' sexual and reproductive health rights, see E Durojaye 'Realising access to contraception for adolescents in Nigeria: A human rights analysis' LLD thesis, University of the Free State, 2010; and Savage-Oyekunle (n 10 above). 


\section{What is emergency contraception?}

Emergency contraceptives are contraceptives that can be used to prevent pregnancy during the first few days after intercourse. ${ }^{21}$ Often referred to as the 'morning-after pill', emergency contraceptives prevent ovulation or fertilisation and are intended for emergency use following unprotected intercourse, contraceptive failure or incorrect use, $^{22}$ rape or coerced sex. ${ }^{23}$

The emergency contraceptive pill may be taken up to 72 hours $^{24}$ after unprotected sex, but is more effective when used within the first 24 hours after sexual intercourse. ${ }^{25}$ While emergency contraceptives should not replace the oral contraceptive pill which is taken daily, the emergency contraceptive pill may be taken by any girl or woman in order to avoid an unwanted pregnancy. ${ }^{26}$

In use since the mid-1960s, emergency contraception initially was developed to treat rape victims in order to prevent unintended pregnancies. $^{27}$ In the early 1970s, the Yuzpe regimen - a combination hormone formula - replaced the high-dose oestrogen emergency contraceptive methods of the 1960s and became the gold standard of treatment for post-coital contraception. ${ }^{28}$ During this period the copper intra-uterine device (IUD) was also introduced and used by health care providers as the only non-hormonal method of emergency

21 Emergency contraceptives are intended for occasional use, when primary methods of contraception fail, in order to prevent the occurrence of pregnancy. See Association of Reproductive Health Professionals 'The difference between medical abortion and emergency contraceptive pills' http://www.arhp.org/publicationsand-resources/clinical-fact-sheets/mifepristone-ec (accessed 2 April 2015).

22 Contraceptive failure or misuse involves situations where the woman or female adolescent forgets to take her daily pill or where a condom becomes damaged during sexual intercourse.

23 WHO Emergency contraception, http://www.who.int/mediacentre/factsheets/ fs244/en/ (accessed 2 June 2016).

24 While data support that EC can be used up to 120 hours after unprotected sexual intercourse, it has been noted that its efficacy diminishes as hormonal administration becomes more remote from the unprotected intercourse event. See American Academy of Paediatrics Policy Statement: Contraception and adolescents (2007) 120 Paediatrics 1144.

25 Emergency contraceptive pills differ from medical abortion pills. While the EC pill is a back-up contraceptive method used to prevent a pregnancy after unprotected sex or contraceptive failure, the medical abortion pill is a non-surgical option for terminating an established pregnancy. See International Consortium for Emergency Contraception 'Emergency contraception and medical abortion: What's the difference?' (2013) http://www.cecinfo.org/custom-content/uploads/ 2014/01/ICEC_Medical-Abortion-Fact-Sheet_Feb-2013.pdf (accessed 23 June 2016).

26 WHO (n 23 above).

27 The treatment adopted then consisted of the use of a high dose of oestrogen after a rape. Though found to be effective, it was discovered that the treatment adopted had many harsh side-effects. See D Stacey 'The history of emergency contraception' https://www.verywell.com/the-history-of-emergency-contracep tion-906714 (accessed 18 June 2016).

28 The Yuzpe regimen was developed by A Albert Yuzpe in 1974. See Stacey (n 27 above); Wikipedia (n 14 above). 
contraception to date. ${ }^{29}$ Although it is an effective form of emergency contraception as it is able to prevent pregnancy for up to five days after unprotected intercourse, the copper-releasing IUD usually is not recommended for use in adolescents. ${ }^{30}$

Regarding the importance of emergency contraception, the Planned Parenthood Organisation explains that it provides women (and adolescent girls) with a second chance to prevent pregnancy in cases of unanticipated sexual activity, contraceptive failure or sexual assault. ${ }^{31}$ Likewise, Babatunde remarks that emergency contraception is a safe, effective and relatively inexpensive means of preventing unplanned pregnancies after unplanned or unprotected sexual intercourse. ${ }^{32}$ According to him, especially because of their earlier and often unplanned initiation into sexual activities, the use of emergency contraceptives in adolescence is particularly appropriate as adolescents often engage in sporadic and occasional sexual encounters which pose a serious challenge to their sexual health. ${ }^{33}$

In addition to providing a second chance to prevent unwanted pregnancies, emergency contraception has been proven safe and effective. It has no long-term effects on the health of the adolescent girl or woman, and does not affect future fertility or increase the risk of ectopic pregnancies. ${ }^{34}$ The Planned Parenthood Organisation explains that two factors influence the effectiveness of the use of emergency contraception, namely, the length of time that elapses after unprotected intercourse; and at which stage during the menstrual cycle of the woman or adolescent it is used. When taken during the first few days after unprotected intercourse this form of contraception is most effective. Also, the closer a woman is to ovulation at the time of unprotected intercourse the less likely the method is to succeed. ${ }^{35}$ However, emergency contraception is not as effective as the consistent use of other regular contraceptive methods, ${ }^{36}$ neither does it protect against STIs and HIV. ${ }^{37}$

29 Stacey (n 27 above); Wikipedia (n 14 above).

30 American Academy of Paediatrics Policy Statement (n 24 above) 1144.

31 Planned Parenthood 'Emergency contraception: History and access' https:// www.plannedparenthood.org/files/5713/9611/6188/

Emergency_Contraception_History_and_Access.pdf (accessed 15 June 2016).

32 OA Babatunde et al 'Knowledge and use of emergency contraception among students of public secondary schools in Ilorin, Nigeria' (2016) 23 Pan-African Medical Journal, http://www.panafrican-med-journal.com/content/article/23/74/ pdf/74.pdf (accessed 9 June 2016).

33 Babatunde et al (n 32 above).

34 International Consortium for Emergency Contraception 'The Unfinished agenda: Next steps to increase access to emergency contraception' (2014) 2, http://www. cecinfo.org/custom-content/uploads/2014/01/ICEC_Next-Steps-WEB_2014.pdf (accessed 23 June 2016).

35 Planned Parenthood (n 31 above).

36 Regular contraceptive methods include the pill, the IUD, implants, injections, patches or rings.

37 Planned Parenthood (n 31 above). See also American Academy of Paediatrics 
We now move on to present a brief outline of guarantees in human rights instruments of the SRH rights of adolescents. Because of the focus of the article, we highlight the rights of female adolescents.

\section{An overview of adolescents' sexual and reproductive health rights}

[A]s a matter of policy, the sexual and reproductive health of adolescents matter because they comprise almost one half of the world's population. As a matter of international human rights law, adolescents have reproductive and sexual health rights. ${ }^{38}$

The period of adolescence is critical: Adolescents transition from being dependents to being providers; and adolescents' health and sexual choices during the period to a large extent shape their futures. ${ }^{39}$ In fact, improvements in the sexual and reproductive health status of a region over time depend on the degree to which governments invest in adolescent sexual health. ${ }^{40}$ The situation is particularly tendentious in the case of adolescent girls as they are constantly faced with peer pressure to engage in early sexual relations, ${ }^{41}$ and also often are victims of sexual violence. ${ }^{42}$

Internationally, apart from the Universal Declaration of Human Rights (Universal Declaration) and other human rights instruments generally recognising the right of everyone to the highest attainable standard of health, ${ }^{43}$ children's rights to sexual and reproductive

Emergency contraception (2012) http://pediatrics.aappublications.org/content/ 130/6/1174 (accessed 8 June 2016).

38 A Haider 'Adolescents under international law: Autonomy as the key to reproductive health' (2008) 14 William and Mary Journal of Women and the Law 605.

39 See Savage-Oyekunle (n 10 above) 21.

40 G Kangaude 'Enhancing the role of health professionals in the advancement of adolescent sexual health and rights in Africa' (2016) 132 International Journal of Gynaecology and Obstetrics (2016) 105.

41 A Ankomah et al 'Reasons for delaying or engaging in early sexual initiation among adolescents in Nigeria' (2011) 2 Adolescent Health, Medicine and Therapeutics 78-80, http://www.pathfinder.org/publications-tools/pdfs/Reasonsfor-delaying-or-engaging-in-early-sexual-initiation-among-adolescents-in-Nigeria. pdf (accessed 8 May 2013); T Selikow et al 'I am not umqwayito: A qualitative study of peer pressure and sexual risk behaviour among young adolescents in Cape Town, South Africa' (2009) 37 Scandinavian Journal of Public Health 109-110; JB Bingenheimer et al 'The peer group context of sexual behaviours among Ghanaian youth', http://paa2013.princeton.edu/papers/131537(accessed 8 May 2013).

42 R Jewkes 'Non-consensual sex among South African youth: Prevalence of coerced sex and discourses of control and desire' in SJ Jejeebhoy et al (eds) Sex without consent: Young people in developing countries (2005) 88; FF Akanle 'Sexual coercion of adolescent girls in Yoruba Land of Nigeria' (2011) 3 Current Research Journal of Social Sciences 132-138; Family Health International 'Non-consensual sex' (2005) 23 Network 3-4, http://lastradainternational.org/lsidocs/583\%20fhi_05_noncon sensual_sex_070402.pdf (accessed 8 May 2013); Ankomah et al (n 41 above) 8182.

43 Art 25 Universal Declaration; art 12 CEDAW; and art 12 ICESCR. See also, generally, paras 14-21 General Comment 22 of the ESCR Committee. 
health were given the status of legally-binding international law with the adoption by the United Nations (UN) Convention on the Rights of the Child (CRC) on 20 November 1989.44 In 1994, at the International Conference on Population and Development (ICPD), 45 governments from all over - including Africa - acknowledged the need to recognise adolescents' sexual and reproductive health rights. ${ }^{46}$ Following the lead of the ICPD, several additional international declarations have urged governments to commit to the realisation of adolescent sexual and reproductive health rights through their access to quality sexual and reproductive health care services. 47

According to Durojaye the adoption of a rights-based approach to realise the rights of adolescents to emergency contraception is necessary as it creates an avenue for holding governments accountable for the fulfilment of adolescents' sexual rights under international and regional human rights law. ${ }^{48}$

In Africa the right of adolescents to sexual and reproductive health care - specifically their right of access to emergency contraception may be inferred from the right to health as recognised in article 16 of the African Charter on Human and Peoples' Rights (African Charter), ${ }^{49}$ and articles 14(1), 14(2)(b) and 14(2)(f) the African Charter on the Rights and Welfare of the Child (African Children's Charter). ${ }^{50}$

Additional rights that are necessary for the enjoyment of adolescents' rights to access emergency contraceptives include the rights to equality (non-discrimination); life; dignity; privacy; information; and education, ${ }^{51}$ also guaranteed in these instruments.

44 The Convention on the Rights of the Child was adopted by Resolution 44/25 of 20 November 1989.

45 The conference resulted in countries committing to the ICPD Programme of Action - A/CONF.171/13/Rev.1, http://www.unfpa.org/public/publications/pid/ 1973 (accessed 20 April 2016).

46 Art 24 of the CRC recognises the rights of children to the enjoyment of the highest attainable standard of health and orders state parties to assure their access to preventive health care, including that relating to family planning education and services. See arts 24(1) \& 24(2)(f) of the CRC. Paras 7.41-7.48 of the ICPD Programme of Action were specifically dedicated to adolescent sexual and reproductive health.

47 Paras 97 \& 98 Beijing Declaration and Platform for Action; African Youth Charter 2009; Bali Global Youth Forum Declaration 2012; and so on.

48 E Durojaye 'Realising access to sexual health information and services for adolescents through the Protocol to the African Charter on the Rights of Women' (2009) 16 Washington and Lee Journal of Civil Rights and Social Justice 152.

49 The African Charter on Human and Peoples' Rights was adopted in 1981; OAU Doc CAB/LEG/67/3 Rev 5. Also see AU Commission (n 18 above).

50 The African Children's Charter was adopted in 1990; OAU Doc CAB/LEG/24.9/49. The rights of African children to access EC may be inferred from the provisions of arts 14(1), 14(2)(b) \& 14(2)(f) of the African Children's Charter which implores state parties to develop preventive health care, family life education and services for children.

51 See generally arts 2, 4, 5, 9 and 17 of the African Charter; arts 3, 5, 9, 10, 11 \& 21 of the African Children's Charter. 
Particularly, article 11(2)(h) of the African Children's Charter makes provision for the 'direction of the education of children towards their understanding of primary health care'. This provision is such that it may be interpreted to accommodate giving adolescent girls information regarding emergency contraceptive services, as the provision of advice on family planning and contraception constitutes a part of primary health care services. Also, the right to privacy protected in the African Children's Charter ${ }^{52}$ is of paramount importance in guaranteeing the protection of the sexual health of adolescent girls in the region. This is so because assurances that their privacy will be protected positively influence adolescent girls' readiness to access emergency contraception where available. ${ }^{53}$

In addition to the above, the African Children's Charter contains three major guarantees which influence adolescent girls' access to emergency contraception in Africa: the best interests of the child; ${ }^{54}$ the right of the child to participate in decisions affecting them; ${ }^{55}$ and the 'evolving capacities of the child' concept. ${ }^{56}$ With the inclusion of these provisions, the Children's Charter demonstrates an acceptance that adolescent girls not only mature at different rates, but that they attain various levels of competence and insight as they grow. Also, it is these levels of competencies that must be considered when adolescent girls require confidential information on emergency contraception or about the services themselves.

Despite these admirable provisions, a major criticism of the African Children's Charter is that it fails adequately to protect the rights of female children in the region because of the gender-insensitive manner in which some of its provisions are couched, thereby trivialising 'adolescent girls' sufferings'. 57 The adoption in 2003 of the Protocol to the African Charter on Human and Peoples' Rights on the Rights of Women in Africa (African Women's Protocol), 58 which focuses on issues that hitherto have not been addressed, and which indirectly domesticates the Beijing Declaration and the ICPD

52 Art 10 African Children's Charter.

53 Adolescent girls will not use contraception, whether regular or emergency, if their rights to privacy and confidentiality are not adequately assured. See R Cook et al 'Respecting adolescents' confidentiality and reproductive and sexual choices' (2007) 98 International Journal of Gynaecology and Obstetrics 186; R Cook \& BM Dickens 'Recognising adolescents' "evolving capacities" to exercise choice in reproductive healthcare' (2000) 70 International Journal of Gynaecology and Obstetrics 17.

54 Art 4 African Children's Charter.

55 Art 4(2) African Children's Charter.

56 Art 9(2) African Children's Charter.

57 See Durojaye (n 48 above) 155.

58 The African Women's Protocol was adopted in 2003, OAU Doc AHG/Res. 240 (XXXI). 
Programme of Action in the African region, ${ }^{59}$ was aimed at correcting criticisms of gender insensitivity levelled against the African Children's Charter. The African Women's Protocol did this through its proactive inclusion of adolescent girls as among the women whom it protects. ${ }^{60}$ Viljoen notes that although the African Women's Protocol was drafted as an addition to the African Charter, unlike its international counterpart, the Convention on the Elimination of All Forms of Discrimination Against Women (CEDAW), the African Women's Protocol expands on the protective scope of women's rights as it addresses concerns that are particular to African women. ${ }^{61}$

Article 14 of the African Women's Protocol protects the sexual and reproductive health of all women and affirms their right to reproductive choice and autonomy. ${ }^{62}$ In relation to adolescent girls' rights to access emergency contraceptive information and services, it recognises the rights of adolescent girls to control their fertility; ${ }^{63}$ to choose any method of contraception; ${ }^{64}$ and to access family planning education. ${ }^{65}$ It also recognises the obligation that African governments adopt all appropriate measures to provide adequate, affordable and accessible health services and information. 66 Thus, with the inclusion of these provisions, the African Women's Protocol actively promotes the recognition of adolescent girls' rights to access information and services on emergency contraceptives in order to prevent unplanned pregnancies.

\section{Nexus between adolescents' sexual and health rights and their access to emergency contraception}

As explained above, ${ }^{67}$ the connection between good sexual health practices by adolescents and their access to sexual and reproductive health care information and services - especially contraceptive information and services, including emergency contraceptives - has

$59 \mathrm{Eg}$, art 6 on marriage specifies the age of 18 as the minimum age of marriage, and requires that both parties to the union give consent and calls for the registration of marriages in order for them to be legally recognised. See F Banda 'Blazing a trail: The African Protocol on Women's Rights comes into force' (2006) 50 Journal of African Law 72-73 76; M Wandia Not yet a force for freedom: The Protocol on the Rights of Women in Africa, http://www.pambazuka.org/en/ publications/africanvoices_chap04.pdf (accessed 18 March 2016).

60 Art 1(k) African Women's Protocol.

61 F Viljoen 'An introduction to the Protocol to the African Charter on Human and Peoples' Rights on the Rights of Women in Africa' (2009) 16 Washington and Lee Journal of Civil Rights and Social Justice 21.

62 E Durojaye \& LN Murungi 'The African Women's Protocol and sexual rights' (2014) 18 International Journal of Human Rights 886.

63 Art 14 (1)(a) African Women's Protocol.

64 Art $14(1)(c)$ African Women's Protocol.

65 Art 14 (1)(f) African Women's Protocol.

66 Art 14(2)(a) African Women's Protocol.

67 See para 2 above. 
received increased attention during over recent decades, with international and regional bodies pledging their commitment towards the recognition of adolescents' rights to access sexual and reproductive health care as a means of fulfilling other rights and meeting development needs. ${ }^{68}$ Thus, attention to the sexual and reproductive health of adolescent girls is closely associated with the need to eradicate poverty and inequality which affect many girls, as a lack of access to sexual and reproductive health care education including important information on where to access emergency contraceptives - cause female adolescents to bear the brunt of society's negligence by giving birth to unplanned and unwanted children. ${ }^{69}$

The importance and relevance of realising adolescents' sexual and reproductive rights in the context of reducing poverty are similarly recognised in the AU Commission's Continental Policy Framework for the Promotion of Sexual and Reproductive Health and Rights in Africa (Continental Policy Framework). ${ }^{70}$ The Continental Policy Framework expressly recognises the connections between poverty and sexual and reproductive health, as well as their importance to sustainable development. $^{71}$

In sub-Saharan Africa, as in the rest of the world, the protection of adolescents' sexual and reproductive health through their access to contraceptive services and information (including emergency contraception) not only generates concern among stakeholders, but also continues to be a constant subject of government policies and programmes due to the spread of HIV and unintended teenage pregnancies in many African countries. ${ }^{72}$ These stakeholders either canvass for the restriction of adolescent girls' access to contraceptives and other sexual and reproductive health care information or services, or champion the increase of their access to the life-saving information and services. 73

68 UNICEF The state of the world's children 2011: Adolescence an age of opportunity (2011) 3, http://www.unicef.org/sowc2011/pdfs/SOWC-2011-MainReport_EN_02092011.pdf (accessed 31 March 2016). Also see OA SavageOyekunle \& A Nienaber 'Adolescent girls' access to contraceptive information and services in South Africa: What is going wrong?' (2015) Journal on Contemporary Roman Dutch Law 363-396.

69 UNICEF (n 68 above) 3; AU Commission (n 17 above) 15.

70 AU Commission (n 17 above) 15.

71 As above.

72 E Yarrow et al 'Can a restrictive law serve a protective purpose? The impact of agerestrictive laws on young people's access to sexual and reproductive health services' (2014) 22 Reproductive Health Matters 148; A Bankole et al 'Sexual behaviour, knowledge and information sources of very young adolescents in four sub-Saharan African countries' (2007) 11 African Journal of Reproductive Health 2930.

73 LL Wynn et al 'Harm reduction or women's rights? Debating access to emergency contraceptive pills in Canada and the United States' (2007) 38 Studies in Family Planning 253-267; V Schiappacasse \& S Diaz 'Access to emergency contraception' (2006) 94 International Journal of Gynaecology and Obstetrics 302; BG Schoepf 
An important issue connected to adolescent girls' sexual health and rights to access emergency contraception relates to the recognition of their autonomy. ${ }^{74}$ Representing an increasing segment in many societies, ${ }^{75}$ adolescents encounter various transitions, including the development of the identity; the acquisition of skills; and a move towards social and economic independence. ${ }^{76}$ In addition, increased physical and sexual maturity leads to the start of sexual activity. ${ }^{77}$

However, the initiation of sexual activity, especially in Africa, gives rise to problems associated with adolescents' rights to access emergency contraception, in particular, and contraceptive information and services, in general. This is so because various stakeholders, including parents, tend to fight for control over the right to determine adolescents' sexual health needs, thus putting them in danger of sexual ill-health and unplanned pregnancies. ${ }^{78}$ Tied to this struggle for control is the realisation that it is in the best interests of adolescent girls to recognise their autonomy and for them to access emergency contraceptives in confidential and adolescent-friendly environments in order to guarantee good sexual health outcomes. ${ }^{79}$

'Uganda: Lessons for AIDS control in Africa' (2003) 30 Review of African Political Economy 554-556; NN Sarkar 'Barriers to emergency contraception (EC): Does promoting EC increase risk for contacting sexually-transmitted infections, HIV/AIDS?' (2008) 62 International Journal of Clinical Practice 1772.

74 Autonomy in this instance refers to 'personal autonomy', ie, the right of individuals to self-determination and taking informed decisions about personal matters without any form of coercion or fear.

75 J Fortin Children's rights and the developing law (2009) 81; A Bankole \& $S$ Malarcher 'Removing barriers to adolescents' access to contraceptive information and services' (2010) 41 Studies in Family Planning 117.

76 WHO Adolescent development: A critical transition, http://www.who.int/maternal child_adolescent/topics/adolescence/dev/en/index.html (accessed 9 May 2013).

77 Studies abound showing that sexual activities usually are initiated during the period of adolescence. See $S$ James et al 'Perceptions of pregnant teenagers with regard to the antenatal care clinic environment' (2012) 35 Curationis 2; M Mantakana Dynamic contextual analysis of adolescent sexual and reproductive health in Peddie, Eastern Cape (2002) 7, http://www.cadre.org.za/files/ DCA_final_report.pdf (accessed 17 June 2016); R Stephenson et al 'Community factors shaping early age at first sex among adolescents in Burkina Faso, Ghana, Malawi, and Uganda' (2014) 32 Journal of Health, Population and Nutrition 161162.

78 While some view adolescents' sexuality as wrong and to be discouraged, others (liberationists) are of the belief that adolescents as rights holders do not deserve to be discriminated against through their exclusion from the adult world. According to them, adolescents possess greater abilities for self-determination than society cares to admit, and there is no reason to prohibit them from enjoying the freedoms granted to adults, including the right to control their sexual lives. Contrary to this view is that of Campbell, eg, who believes that adolescents will be under constant stress if, like adults, they are to make rational decisions for themselves. See Fortin ( $\mathrm{n} 75$ above) 4-5; TD Campbell 'The rights of the minor: As person, as child, as juvenile, as future adult' (1992) 6 International Journal of Law, Policy and the Family 1-23.

79 See Savage-Oyekunle (n 10 above) 149-182. 
In Gillick $v$ West Norfolk and Wisbech Area Health Authority \& Another, 80 the court held that a doctor would not be acting unlawfully if he gave contraceptive advice or treatment to an adolescent who is 'Gillick competent' ${ }^{81}$

Another means of achieving adolescent girls' access to emergency contraceptives involves the adoption of approaches that guarantee access to factual sexuality information coupled with access to affordable and accessible emergency contraceptive services in general. $^{82}$ In a review of emergency contraception literature from various countries - including developing countries - Family Health International notes that in all countries there is little awareness of the existence of emergency contraceptives. ${ }^{83}$ Even in countries where this concept is known, knowledge regarding its accurate use is low. In Tanzania, for example, although government policies support the use of emergency contraception and advise that the pills should be made available at every level of the health system, the use of emergency contraception remains low due to a lack of knowledge about their availability. ${ }^{84}$ In fact, in a Nigerian study adolescent girls identified

80 (1986) 1 AC 112, (1985) 3 All ER 40. The House of Lords was of the opinion that once an adolescent girl under the age of 16 understood the nature of sexual and reproductive health care services she requested and its implications, she should be granted access to the treatment in confidential settings without parental consent.

81 The Gillick competent child is one who can personally consent to medical services, including emergency contraceptives. The principle was laid down with the House of Lords agreeing that the competence of adolescents to consent to treatment has evolved to the extent that it is to be measured based on their level of maturity and not age. In the $R(A x o n)$ case, the courts adopting the decision in the Gillick case, reached the decision that female adolescents that are Gillick competent, were entitled to confidential health care services, in the same way as adults, in order to forestall situations where the adolescents will be further exposed to SRH ills. See also Christian Lawyers Association v Minister of Health (Christian Lawyers case 2) 2005 (1) SA 509 (T); The Teddy Bear Clinic for Abused Children \& Another v Minister of Justice and Constitutional Development \& Another (CCT 12/13) [2013] ZACC 35; and Savage-Oyekunle \& Nienaber (n 13 above) 377-379.

82 WHO Cutting-edge global research on family planning and improving adolescent sexual and reproductive health (2012) 2, http://apps.who.int/iris/bitstream/10665/ 76235/1/WHO_RHR_HRP_12.30_eng.pdf (accessed 23 March 2016); UNFPA Community pathways to improved adolescent sexual and reproductive health: $A$ conceptual framework and suggested outcome indicators (2007) 2, http:// www.unfpa.org/webdav/site/global/shared/documents/publications/2007/ asrh_pathways.pdf (accessed 23 March 2016); para 107(e) Beijing Declaration and Platform of Action (1995) http://www.unesco.org/education/information/ nfsunesco/pdf/BEIJIN_E.PDF (accessed 23 March 2016).

83 Family Health International Adolescents and emergency contraceptive pills in developing countries (2005) 6, http://ec.princeton.edu/references/ecpsadolescents.pdf (accessed 23 June 2016).

84 GAB Kagashe et al 'Availability, awareness, attitude and knowledge of emergency contraceptives in Dar Es Salaam' (2014) 6 Journal of Pharmaceutical Sciences and Research 16-17. Also see the Tanzanian President's recent decree banning pregnant girls from attending school: R Ratcliffe 'After getting pregnant, you are done' The Guardian 30 June 2017, https://www.theguardian.com (accessed 24 September 2017). 
their peers and friends as their major source of information on emergency contraception - not government health initiatives. ${ }^{85}$

In Uganda, although emergency contraception was re-introduced in 2007 after a period of government restriction, ${ }^{86}$ more than twothirds of Ugandan women and adolescent girls have never heard of it, and consequently its use remains very low. ${ }^{87}$ This lack may be the result of the fact that Uganda has banned comprehensive sexuality education in its schools due to religious and societal opposition. ${ }^{88}$ Uganda further has a very high unsafe abortion rate which contributes to the high maternal mortality rate in that country. ${ }^{89}$ Emergency contraception may help reduce the rate of unwanted pregnancies, so reducing the high rate of unsafe abortions.

The same problem of access to accurate knowledge about emergency contraceptive use is observed in Nigeria and Ghana, where only 12 per cent and 11 per cent respectively of adolescents know the correct time frame for starting emergency contraception. ${ }^{90}$ In South Africa, even though several contraceptive methods are available withour charge at public hospitals - including emergency contraceptives - its utilisation among sexually-active adolescents remains relatively low. ${ }^{91}$

Restricted access to sexual and reproductive health care services, generally, and contraceptives (including emergency contraception), in particular, negatively impacts adolescents. This negative impact is

85 IU Ezebialu \& AC Eke 'Knowledge and practice of emergency contraception among female undergraduates in South Eastern Nigeria' (2013) 3 Annals of Medical and Health Sciences Research 7, http://www.ncbi.nlm.nih.gov/pmc/ articles/PMC3868120/?report=reader (accessed 23 June 2016).

86 The restriction on emergency contraception use in the country was as a result of the backlash from religious leaders, who requested the government to stop efforts at promoting emergency contraceptives because it was an abortifacient. See International Consortium for Emergency Contraception (2014) http:// www.cecinfo.org/custom-content/uploads/2014/04/ICEC_UgandaFactsheet_2014.pdf (accessed 23 June 2016).

87 As above; JK Byamugisha Emergency contraception among young people in Uganda: User and provider perspectives (2007) 21.

88 See S Singh 'Hospital admissions resulting from unsafe abortion: Estimates from 13 developing countries' (2006) 368 The Lancet 1887. Again, in 2016, the teaching of comprehensive sexuality education was banned in Uganda and efforts are currently being made to ensure its reversal. See Rutgers Ugandan youth challenge ban on sexuality education (2016) https://www.rutgers.international/ news-opinion/news-archive/ugandan-youth-challenge-ban-sexuality-education (accessed 26 September 2017); A Fallon NGOs turn to courts to unravel Uganda's ban on sexual education (2017) https://www.devex.com/news/ngos-turn-tocourts-to-unravel-uganda-s-ban-on-sexual-education-89979 (accessed 26 September 2017).

89 Singh (n 88 above).

90 Family Health International (n 83 above) 6; Ezebialu \& Eke (n 83 above) 3-4.

91 ME Hoque \& S Ghuman 'Knowledge, practices, and attitudes of emergency contraception among female university students in KwaZulu-Natal, South Africa' (2012) 5 PLOS One, https://www.researchgate.net/publication/2322271 07_Knowledge_Practices_and_Attitudes_of_Emergency_Contraception_among_Fe male_University_Students_in_KwaZulu-Natal_South_Africa (accessed 24 June 2016). 
seen in higher rates of unwanted pregnancies among adolescents. ${ }^{92}$ In a community-based study on abortion prevalence rates in Nigeria, it was revealed that a third of the women who obtained abortion procedures were adolescents who, due to the stringent anti-abortion laws in the country, ${ }^{93}$ end up patronising quacks under unsafe conditions. ${ }^{94}$ Also, in Côte d'Ivoire where restrictive abortion laws are in place, it was revealed that 70 per cent of abortions are carried out on girls and women aged 13 to 24, with the agreement of their parents or partners and upon payment of huge sums of money to health-care providers who do so illegally. ${ }^{95}$ In that country, those who cannot afford this expense are compelled to undergo backstreet abortion procedures which often have disastrous consequences. ${ }^{96}$ It is necessary to highlight that even in countries in Africa where abortion is legal, such as in South Africa, ${ }^{97}$ young women still face barriers which cause them to undergo unsafe procedures. ${ }^{98}$

Adolescents not only experience unplanned and unwanted pregnancies, but also early child bearing which is linked to increased maternal mortality and morbidity rates. ${ }^{99}$ Especially in the African region early pregnancy is a major cause of death and illness among adolescent girls between the ages of 15 to 19 years, who experience disabilities associated with early sexual initiation, pregnancy and child

92 IPPF Qualitative research on legal barriers to young people's access to sexual and reproductive health services (2014) 6, http://www.ippf.org/sites/default/files/ ippf_coram_final_inception-report_eng_web.pdf (accessed 9 June 2016).

93 The performance of abortion is illegal under Nigerian criminal law, unless the woman's life is threatened by the pregnancy. See secs $228 \& 229$ of the Criminal Code Cap c38LFN 2004 and secs 232 \& 233 Penal Code Cap p3 LFN 2004.

94 Babatunde et al (n 32 above) 23.

95 A Ouattara Health - Côte d'Ivoire: Abortion - Illegal, sought after, sometimes fatal (2016) http://www.ipsnews.net/2006/08/health-cote-divoire-abortion-illegalsought-after-sometimes-fatal/ (accessed 24 June 2016).

96 As above.

97 South Africa is one of the few African countries where the procurement of an abortion upon a woman or adolescent girl's request is legal, based on the provisions of the Choice on Termination of Pregnancy Act 92 of 1996. See, generally, secs $2 \& 5(2)(3)$ of the CTOP Act; 'Unsafe abortion in South Africa: A preventable pandemic' (2012) http:://www.ngopulse.org/blogs/unsafe-abortionsouth-africa-preventable-pandemic (accessed 9 June 2016); C MacPhail 'Contraception use and pregnancy among 15-24 year-old South African women: A nationally representative cross-sectional survey' (2007) 5 BMC Medicine http:// www.biomedcentral.com/1741-7015/5/31 (accessed 23 June 2016).

98 ME Ratlabala et al 'Perceptions of adolescents in low resourced areas towards pregnancy and the choice on termination of pregnancy (CTOP)' (2007) 30 Curationis 29.

99 Current estimates of maternal mortality in sub-Saharan Africa for 2014 according to the WHO is 510 per 100000 live births. Nigeria and the Democratic Republic of Congo have a MMR of 560 and 730 per 100000 live births, respectively. See WHO Maternal mortality 2014 report https://docs.google.com/spreadsheets/d/ 16jlHaWXO1zFxfW2Va8kTrfZRhfAFwkdyrLxPJP05rBs/edit?pref=2\&pli=1\#gid=9958 52383 (accessed 24 June 2016); S Ramos 'Interventions for preventing unintended pregnancies among adolescents' (2011) WHO Reproductive Health Library Commentary http://apps.who.int/rhl/adolescent/cd005215_ramoss_com/ en/index.html (accessed 10 June 2016); IS Gupta Human rights of minority and women: Human rights and sexual minorities (2005) 266-267. 
birth due to their lack of physiological development, and emotional immaturity making them unable to adequately care for a child. ${ }^{100}$ These drawbacks underscore the urgency of guaranteeing adolescents' access to accurate information on contraceptives including emergency contraceptives - and quality adolescent-friendly sexual health care services.

Nevertheless, as shown above, adolescents possess only limited knowledge about contraceptives, generally, and emergency contraceptives in particular. It has also been shown that they lack access to sexual health care services or do not feel comfortable using these. ${ }^{101}$ A gradual increase in the age at which young people get married has also ensured that greater numbers engage in premarital sexual intercourse and, therefore, leads to an increase in unwanted pregnancies. ${ }^{102}$ According to the Demographic and Health Surveys (DHS) in Ghana, 103 Kenya ${ }^{104}$ and Namibia, ${ }^{105}$ the proportion of currently-pregnant women under the age 20 who reported that their pregnancies were mistimed or unplanned was 42 per cent, ${ }^{106} 52,7$ per cent ${ }^{107}$ and 30,2 per cent ${ }^{108}$ respectively.

Given the high levels of unwanted adolescent pregnancies in Africa, it is self-evident that emergency contraception is an under-utilised method of primary pregnancy prevention, especially given its potential to reduce the number of unplanned pregnancies and, therefore, unsafe abortions. ${ }^{109}$ Ojule et al remark that emergency contraceptives have a considerable role to play in reducing the rates of unwanted pregnancies and unsafe abortions. ${ }^{110}$ However, low literacy levels, limited access to emergency contraceptive services and traditional beliefs that impede the use of modern contraceptive methods pose considerable challenges to their promotion. ${ }^{111}$

Sexual violence against women and female adolescents is one of the most pernicious consequences of the continued presence of economic, social and cultural inequalities between men and

100 Ramos (n 99 above); Gupta (n 99 above) 266-267.

101 See also Savage-Oyekunle \& Nienaber 'Female adolescents' evolving capacities' (n 13 above) 377-379.

102 Family Health International (n 83 above) 1.

103 Demographic Health Survey Ghana (2014) http://dhsprogram.com/pubs/pdf/ FR307/FR307.pdf (accessed 23 June 2016).

104 Demographic Health Survey Kenya (2014) http://dhsprogram.com/pubs/pdf/ FR308/FR308.pdf (accessed 23 June 2016).

105 Demographic Health Survey Namibia (2013) https://dhsprogram.com/pubs/pdf/ FR298/FR298.pdf (accessed 23 June 2016).

106 Demographic Health Survey Ghana (n 103 above).

107 Demographic Health Survey Kenya (n 104 above).

108 Demographic Health Survey Namibia (n 105 above).

109 JD Ojule et al 'Awareness and practice of emergency contraception among students of university of Port Harcourt, South-South Nigeria' (2008) 8 Nigerian Health Journal 6.

110 As above.

111 Ojule et al (n 109 above) 6. 
women. ${ }^{112}$ According to available data from the World Health Organization (WHO), one-third of women world-wide will experience violence in their lifetime; an estimated 7,2 per cent of women will be sexually assaulted and many more will experience unwanted sex from an intimate partner. Compounding the trauma of sexual violence and rape are fears of and unwarranted exposure to the risk of pregnancy and exposure to STIs and HIV. ${ }^{113}$

In Africa and the rest of the world, adolescents are constantly subjected to various forms of sexual violence in their homes, schools and communities. In Kenya, the African Child Policy Forum in a 2010 survey discovered that schools were the second-most common location for the perpetuation of sexual violence against girls aged 13 to 17. In Sierra Leone' 30 per cent of reported rapes were schoolrelated. Similarly, in Swaziland it was revealed that one-third of adult women experienced some form of sexual violence as an adolescent. ${ }^{114}$ Plummer and Njuguna note that constant sexual abuse is a significant problem in many African countries, with girls experiencing sexual violence at a younger age than boys. ${ }^{115}$ Female victims have a higher risk of experiencing unplanned pregnancies and HIV. ${ }^{116}$

While some African countries have developed policies for the management of sexual assault and to provide post-rape care, ${ }^{117}$ others do not have specific guidelines that may be followed in treating victims of sexual violence. ${ }^{118}$ Specifically in relation to Nigeria, there is

112 Centre for Reproductive Rights The reproductive rights of adolescents: $A$ tool for health and empowerment (2008) 11, http://www.reproductiverights.org/sites/ default/files/documents/adolescents\%20bp_FINAL.pdf (accessed 25 June 2016).

113 International Consortium for Emergency Contraception EC for rape survivors: $A$ human rights and public health imperative (2013) https://www.ciaonet.org/ attachments/27634/uploads (accessed 23 June 2016).

114 The African Child Policy Forum The African report on violence against children (2014) xii http://srsg.violenceagainstchildren.org/sites/default/files/documents/ docs/african report on violence against children 2014.pdf (accessed 23 June 2016); AM Krolikowski \& A Koyfman 'Emergency centre care for sexual assault victims' (2010) 2 African Journal of Emergency Medicine 25.

115 CA Plummer \& W Njuguna 'Cultural protective and risk factors: Professional perspectives about child sexual abuse in Kenya' (2009) 33 Child Abuse and Neglect 524-532. This does not mean that boys cannot be victims of sexual assault. See Krolikowski \& Koyfman (n 114 above) 25.

116 S Mavundla \& C Ngwena 'Access to legal abortion for rape as a reproductive health right: A commentary on the abortion regimes of Swaziland and Ethiopia' in C Ngwena \& E Durojaye (eds) Strengthening the protection of sexual and reproductive health and rights in the African region through human rights (2014) 61.

117 Countries such as Botswana (2012), South Africa (2004), Ethiopia (2009), Tanzania (2012), Kenya (2013) and Uganda (2007) have official national guidelines for the management of rape and sexual assault.

118 Burkina Faso, Burundi, Ghana, Nigeria and Senegal do not have specific national guidelines on post-rape care, even though elements of care that can be given to the victims may be contained in other policies. See J Thompson et al Access to emergency contraception and safe abortion services for survivors of rape: A review of policies, programmes and country experiences in sub-Saharan Africa (2014) 9, http:// www.popcouncil.org/uploads/pdfs/2014STEPUP_EC-SA_Report.pdf (accessed 25 June 2016). 
no policy (whether local or national) that addresses the clinical management needs of rape survivors in that country. ${ }^{119}$

The administration of emergency contraceptives has consistently been identified as one of the minimum core requirements for the post-rape care of victims of sexual violence, as up to 5 per cent of sexual assault victims fall pregnant as a result of the assault. ${ }^{120}$ Consequently, as a matter of respect for the human rights of female adolescents and a public health imperative, it is essential that emergency contraceptives are readily available in emergency health care facilities. However, while HIV prevention treatments tend to be readily available, emergency contraception often is inaccessible despite the reality that the risk of an unintended pregnancy occurring is as high as the risk of HIV infection. ${ }^{121} \mathrm{~A}$ case in point is that of the Democratic Republic of the Congo (DRC) where, despite high rates of sexual violence, access to emergency contraception is absent from key national health policies, and is not used in post-rape care. ${ }^{122}$ This is so despite the fact that the WHO's Global Guidance on Sexual Violence recommends the provision of emergency contraceptives as an integral part of prompt and comprehensive women-centred sexual and reproductive health care. ${ }^{123}$

\section{Challenges to adolescents' access to emergency contraception: A case study of Nigeria}

\subsection{Introduction}

The provision of detailed and accurate sexual and reproductive health care information and services is a significant factor in ensuring that

119 Thompson (n 118 above) 10.

120 Other minimum core requirements include the conduct of a medical examination, counselling and the administration of anti-retroviral medicines to prevent HIV and STIs. On-site immediate pregnancy testing should also be conducted and a positive test within five days of the assault indicates a pre-assault pregnancy. See Krolikowski \& Koyfman (n 114 above) 26.

121 International Consortium for Emergency Contraception EC for rape survivors (n 113 above); ACLU Ensuring access to emergency contraception after rape https:// www.aclu.org/ensuring-access-emergency-contraception-after-rape (accessed 25 June 2016). Recently, a case was instituted against the Peruvian government at the Inter-American Commission on Human Rights as a result of its ban on access to EC even for victims of sexual violence; see CRR 'New human rights case filed on behalf of Peruvian rape survivor denied emergency contraception at public hospital' (2016) http://www.reproductiverights.org/press-room/new-humanrights-case-filed-on-behalf-of-peruvian-rape-survivor-denied-emergency-contracep tion (accessed 26 June 2016).

122 International Consortium for Emergency Contraception Counting what counts: Tracking access to emergency contraception in Democratic Republic of the Congo (2015) http://www.cecinfo.org/custom-content/uploads/2015/07/ICEC_DRC_ July-2015.pdf (accessed 25 June 2016).

123 WHO Responding to intimate partner violence and sexual violence against women: Clinical and policy guidelines (2013) 5, http://apps.who.int/iris/bitstream/10665/ 85240/1/9789241548595_eng.pdf (accessed 24 June 2016). 
the sexual and reproductive rights of people are fulfilled. ${ }^{124}$ Ensuring that female adolescents in Africa have access to complete information on contraceptives (including on emergency contraception) and other sexual and reproductive health issues from an early age facilitates the development of their autonomy which, in turn, allows them to make informed choices about their sexual health later in life. ${ }^{125}$

In particular, guaranteeing adolescents access to various emergency contraceptive options is germane to their enjoyment of the right to sexual and reproductive health care as guaranteed in various human rights instruments. The Committee on the Rights of the Child (CRC Committee) has often reiterated that the obligation to respect, protect and fulfil the rights of children includes a duty to ensure that adolescents not only have access to available sexual and reproductive health information which is essential for their health and development, but also that they have access to available contraceptive methods of appropriate quality according to their evolving capacities. $^{126}$ Regrettably, however, adolescent girls encounter numerous challenges in obtaining factual information about emergency contraception and where to access these pills, ${ }^{127}$ and thus are adversely affected. ${ }^{128}$

\subsection{Challenges}

A number of challenges hinder adolescents' access to emergency contraceptives. First are laws and policies restricting adolescents' access to the medication. According to Gupta, although the majority of governments that are state parties to conventions guaranteeing the right to health and thus the right to sexual health care information and services, in compliance with their obligations, seek to fulfil the rights of women and female adolescents to sexual health care, in many of these countries the choice of whether to use emergency

124 CRR Submission to the Committee on the Rights of Persons with Disabilities (2013) 2, http://www.ohchr.org/EN/HRBodies/CRPD/Pages/DGD17April2013.aspx (accessed 21 June 2016).

125 UNFPA Comprehensive sexuality education: Advancing human rights, gender equality and improved sexual and reproductive health (2010) 12, http://www.unfpa.org/ webdav/site/global/groups/youth/public/Comprehensive\%20Sexuality\%20Educa tion\%20Advancing\%20Human\%20Rights\%20Gender\%20Equality\%20and\%20Im proved\%20SRH-1.pdf (accessed 8 October 2013).

126 Paras 35(b) \& (c) \& 37 CRC Committee General Comment 4 Compilations of General Comments and Recommendations Adopted by Human Rights Treaty Bodies, Vol II, http://www.bayefsky.com/general/hri_gen_1_rev9_vol_ii.pdf (accessed 21 June 2016); C Ngwena Sexual health and human rights in the African region (2011) 206-207 http://www.ichrp.org/files/papers/185/140_Ngwena_Africa_2011.pdf (accessed 9 October 2013).

127 Gupta (n 99 above) 266.

128 C Ngwena 'Introduction to the symposium issue: Reproductive and sexual health and the African Women's Protocol' (2009) 16 Washington and Lee Journal of Civil Rights and Social Justice 4; CRR Submission to the CRPD Committee (n 124 above) 4; $\mathrm{K}$ Casey Adolescent reproductive health in Nigeria (2001) http://www. advocatesforyouth.org/storage/advfy/documents/fsnigeria.pdf (accessed 8 June 2016). 
contraceptives or not is not in women's hands. ${ }^{129}$ Hurdles are placed in their way by anti-choice parties who seek to block access to the emergency contraceptives by all means, thereby forcing governments to declare them to be abortifacients. ${ }^{130}$

The existence of clear policies on emergency contraception promotes their use and availability. If this type of contraception is not included in family planning programmes and are available on prescription only, health care providers are at a loss: It is only through the existence of clear provisions regarding their availability and use that health care providers are able to recommend emergency contraceptives to adolescents who need them. For example, emergency contraceptives are neither included on the DRC's Essential Medicines List, nor in that country's national health policies, despite the fact that the DRC has a very high rate of sexual violence. ${ }^{131}$ In Nigeria, although registered, emergency contraceptives are not included on the country's Essential Drugs List. ${ }^{132}$

It should be noted that it is very important that emergency contraception be accessed on an over-the-counter-basis. This need is because the requirement for a prescription entails the adolescent making two trips: first to the hospital to get a prescription; and, second, to a pharmacist to buy the emergency contraceptives. This demand creates unnecessary obstacles and significantly encroaches on the use of emergency contraception during the 'safety window'. ${ }^{133}$ In $R$ (Smeaton) $v$ Secretary of State for Health, ${ }^{134}$ the courts in the United Kingdom held that the sale of emergency contraception was not prohibited by the Offences Against the Person Act ${ }^{135}$ and, therefore, refused an application that its over-the-counter sale be restricted. In that case, the claimant challenged the prescription of the morningafter-pill on grounds that using the pill would cause miscarriages, and that its use would be an offence under the 1861 Act. In reaching the decision that the morning-after-pill was not an abortifacient, the judge explained that '[t]he 1861 Act was an "always speaking" Act,

129 Gupta (n 99 above) 254.

130 In Uganda, EC was re-introduced in 2007 after a period of government restriction due to protests by religious bodies who viewed it as an abortifacient. See International Consortium for Emergency Contraception Counting what counts (n 122 above); D Uberoi \& $M$ de Bruyn 'Human rights versus legal control over women's reproductive self-determination' (2013) 15 Health and Human Rights 163.

131 International Consortium for Emergency Contraception (n 122 above).

132 Population Council Nigeria Day of dialogue: Expanding opportunities for increased access to emergency contraception (EC) in Nigeria (2013) 5, 6 \& 12 http:// www.popcouncil.org/uploads/pdfs/2013RH_DayOfDialogueEC-Nigeria.pdf (accessed 25 October 2016).

133 As above.

$134 R$ (Smeaton) $v$ Secretary of State for Health [2002] EWHC 886 (Admin) http:// swarb.co.uk/regina-smeaton-v-secretary-of-state-for-health-and-others-admn-18apr-2002/ (accessed 7 September 2017).

135 Offences Against the Person Act 1861. 
and was to be interpreted according to current understanding and not as in $1861^{\prime}$. The judge in fact noted that ${ }^{136}$

[t]here would in my judgment be something very seriously wrong, indeed grievously wrong with our system ... by which I mean not just our legal system but the entire system by which our polity is governed if a judge in 2002 were to be compelled by a statute 141 years old to hold that what ... millions, of ordinary honest, decent, law-abiding citizens have been doing day in day out for so many years is and always has been criminal. I am glad to be spared so unattractive a duty.

In addition, the limited availability and the high cost of emergency contraception are barriers that prevent adolescents' use of the contraception. Adolescents will forgo the use of emergency contraception where it is not readily available at public health centres and can only be accessed from expensive private sources. ${ }^{137}$

Furthermore, another impediment which affects access to emergency contraceptives involves the use of 'conscience' clauses ${ }^{138}$ that allow health care providers (and pharmacists) to refuse to provide emergency contraception pills and other contraceptive methods to adolescents and women because of their religious inclinations. This loophole significantly affects adolescents' ability to access emergency contraceptives within the 120-hour time frame when they are most effective. 139

Another challenge faced by adolescents who access emergency contraception relates to their lack of knowledge about the various types of contraceptives, including emergency contraceptives. Hooja and Mital state that although adolescents may be aware of the existence of emergency contraceptives, they generally are not properly informed as to the correct time frame for starting treatment. ${ }^{140}$ In fact, even though adolescents may have heard about emergency contraceptives, their use as a method of birth control after unprotected sexual relations is very low due to misconceptions that range from viewing them as an abortifacient to a belief that they will make them infertile. ${ }^{141}$ Babatunde et al are of the opinion that the low prevalence rates of contraceptive use (including that of emergency contraception) may also be tied to poor societal attitudes towards adolescent sexuality in African communities. ${ }^{142}$ Isa et al in a

136 Smeaton (n 134 above).

137 Family Health International (n 83 above) 9.

138 Conscience clauses are legal clauses that allow health care providers to refuse to provide some services on the premise that such medical services are against their religion and conscience.

139 International Consortium for Emergency Contraception Legal and Opposition Issues http://www.cecinfo.org/ec-issues/legal-opposition-issues/\#a (accessed 26 June 2016).

$140 \mathrm{~N}$ Hooja \& P Mital 'Knowledge, attitude and practices relating to emergency contraception among college girls and their mothers' (2012) 16 Internet Journal of Gynaecology and Obstetrics http://print.ispub.com/api/0/ispub-article/13854 (accessed 9 June 2016).

141 Babatunde et al (n 32 above) 23. 
study of the unmet need for emergency contraceptives among female adolescents in the Niger Delta also note that young women seeking to access sexual health care services (especially for contraception) face social and cultural obstacles which make it difficult for them to access effective contraception, thereby exposing them to the risk of unsafe abortions. ${ }^{143}$ According to Amnesty International, the lack of access to information on sexual and reproductive health rights combined with women's low socio-economic status within the family and society at large, among others, are dominant factors undermining their right to exercise autonomy over their own sexual and reproductive health. 144

Even where knowledge exists about the existence of emergency contraception, the capacity of adolescents to give consent to medical treatment is another problem affecting their uptake of emergency contraception and other sexual and reproductive health care services. ${ }^{145}$ In addition, unfriendly and judgmental attitudes among health care providers negatively affect adolescents' access to emergency contraceptives. According to Family Health International, in Zambia and Zimbabwe, adolescents see health care providers in government hospitals as unwelcoming and judgmental. ${ }^{146}$ These health care providers not only make adolescents feel embarrassed, but they strip them of their right to privacy as their services are not rendered in a confidential environment. ${ }^{147}$

142 Babatunde et al 23; PB Gichangi et al 'Knowledge, attitudes, and practices regarding emergency contraception among nurses and nursing students in two hospitals in Nairobi, Kenya' (1999) 59 Contraception 253-256.

143 Isa et al 'Unmet need of emergency contraceptives: The curious scenario of female undergraduates in the Niger Delta' (2015) 5 British Journal of Medicine and Medical Research 1393.

144 G Mirugi-Mukundi 'A human rights-based approach to realising access to sexual and reproductive health rights in sub-Saharan Africa' in E Durojaye (ed) Litigating the right to health in Africa: Challenges and prospects (2015) 52.

145 The age of consent to medical treatment varies from country to country. In Nigeria, the position adopted in relation to consent is paternalistic as adolescents and children generally cannot make any medical decisions, including those relating to the protection of their SRH until they are 18 years of age. It is even more disappointing that the National Health Act 2014 does not rectify the problem. In South Africa, the age of 12 is the threshold for adolescents giving consent for medical treatment and accessing contraceptives so far as it has been established that the child possesses sufficient maturity and mental capacity to understand the benefits and risks associated with the treatment proposed. See secs 129 and 134(1) of the Children's Act. For termination of pregnancy in South Africa, however, the threshold of 12 years does not apply as the CTOP Act 1996 allows a woman of 'any age' to give consent to the termination of her pregnancy. See secs 1(xi) and 5(1)(2) \& (3) of the Choice on Termination of Pregnancy Act. Also in countries such as The Gambia, Ghana and Kenya, the age of majority is 18 years.

146 Family Health International (n 83 above) 7. See also Hooja and Mital (n 140 above) 16.

147 RS Geary et al 'Evaluating youth-friendly health services: Young people's perspectives from a simulated client study in urban South Africa' (2015) 8 Global Health Action http://www.globalhealthaction.net/index.php/gha/article/view/ 26080 (accessed 20 July 2016); E Durojaye 'Children and adolescents' access to 
In addition, as a result of socio-cultural beliefs, health care providers, parents and even policy makers fear that adolescents' use of emergency contraception will lead to their engaging in unprotected sexual intercourse more readily, thereby limiting their use of regular contraceptive methods. ${ }^{148}$ However, it is important to stress that this belief is unfounded as studies on emergency contraceptives reveal that their use does not necessarily expose adolescents to greater risks of STIs and HIV infection, as those who use emergency contraception are not less likely to use other methods of contraception. Instead, adolescents' access to emergency contraception may provide them with an opportunity to learn about the availability of regular contraceptive methods. ${ }^{149}$

Other challenges affecting the use of emergency contraceptives by adolescents in Africa include inconvenient operating hours at adolescent-friendly clinics; adolescents having to travel long distances to access emergency contraceptive services; and the fact that the majority of health care providers are not properly trained in the provision of emergency contraceptives. ${ }^{150}$

Another important hurdle to the uptake of emergency contraception is the fact that in many African countries these contraceptives are accessed in the private health care service only, causing them to be more expensive than other contraceptive methods. In Kenya, for example, private sector pharmacies account for as much as 94 per cent of emergency contraceptive sales. ${ }^{151}$

Below we examine Nigerian adolescents' access to emergency contraception as guaranteed in the Nigerian Constitution, legislation and policies. We briefly investigate the realisation of those guarantees in adolescents' access (or lack thereof) to emergency contraception in Nigeria.

reproductive and sexual healthcare' in IO lyioha \& RN Nwabueze (eds) Comparative health law and policy: Critical perspectives on Nigerian and global health law (2015) 155; G Nalwadda et al 'Persistent high fertility in Uganda: Young people recount obstacles and enabling factors to use of contraceptives' (2010) 10 BMC Public Health 7 http://www.ncbi.nlm.nih.gov/pmc/articles/PMC2940919/ pdf/1471-2458-10-530.pdf (accessed 20 July 2016).

148 Family Health International (n 83 above) 7-8.

149 JE Luziga 'Implementation processes of emergency contraception in Tanzania: The case of three wards of Nyamagana district - Mwanza' Muhimbili University of Health and Allied Sciences (2013) 23; IPPF Qualitative research on legal barriers to young people's access (n 93 above); Family Health International (n 83 above) 7-8.

150 Family Health International (n 83 above) 7.

151 As above. 


\subsection{Nigerian adolescents' access to emergency contraceptives: A case study}

As the country with the largest population on the African continent, Nigeria's population totals over 182 million people, ${ }^{152}$ and adolescents represent over 22 per cent ${ }^{153}$ of this total. As is the case with their counterparts in the rest of Africa and the world, Nigerian adolescents often are sexually active at a young age. ${ }^{154}$ This activity comes with the risks usually associated with adolescent sexual behaviour, including unplanned and unwanted pregnancies. ${ }^{155}$

The large number of adolescents in Nigeria, coupled with the fact that many of them are sexually active, makes it critical that their sexual health is protected through their unhindered access to emergency contraception and other sexual health care services and information. ${ }^{156}$

152 United Nations Department of Economic and Social Affairs/Population Division World Population Prospects: The 2015 Revision, Volume II (2015) 567, https:// esa.un.org/unpd/wpp/Publications/Files/WPP2015_Volume-II-Demographic-

Profiles.pdf (accessed 15 October 2016).

153 R Cortez et al Adolescent sexual and reproductive health in Nigeria (2015) 1 http:// documents.worldbank.org/curated/en/199031468290139105/pdf/950290BRI00 PUBOgeria0VCOADDOSERIESO.pdf (accessed 18 October 2016).

154 BO Idonije et al 'A study on knowledge, attitude and practice of contraception among secondary school students in Ekpoma, Nigeria' (2011) 2 Journal of Pharmacy and Clinical Sciences 26; A Attahir et al 'Knowledge, perception and practice of emergency contraception among female adolescent hawkers in Rigasa sub-urban community of Kaduna State Nigeria' (2010) 4 Journal of Family and Reproductive Health 15-20; IO Morhason-Bello et al 'Sexual behaviour of in-school adolescents in Ibadan South-West Nigeria' (2008) 12 African Journal of Reproductive Health 94.

155 A Bankole et al Unwanted pregnancy and induced abortion in Nigeria: Causes and consequences (2006) 4 http://www.guttmacher.org/pubs/2006/08/08/Nigeria-UPIA.pdf (accessed 14 September 2016); AA Galbraith et al 'Health care access and utilisation among pregnant adolescents' (1997) 21 Journal of Adolescent Health 253; L Ikamari \& R Towett 'Sexual initiation and contraceptive use among female adolescents in Kenya' (2007) 14 African Journal of Health Sciences 1-2.

156 It is necessary to highlight that the large population of adolescents in the country gives rise to an opportunity to hasten economic development and minimise poverty. It often has been reiterated that an investment in the SRH of adolescents is an investment in a better future. See Population Reference Bureau The time is now: Invest in sexual and reproductive health for young people (2012) http:// www.prb.org/pdf12/engage-youth-key-messages.pdf (accessed 20 October 2016); UNICEF (n 68 above) 4-5; Bankole \& Malarcher (n 75 above) 117; J Chaaban \& W Cunningham Measuring the economic gain of investing in girls: The girl effect dividend (2011) $3 \mathrm{http} / / / \mathrm{www}$-wds.worldbank.org/servlet/WDSContent Server/WDSP/IB/2011/08/08/000158349_20110808092702/Rendered/PDF/WPS 5753.pdf (accessed 20 October 2016); EY Jimenez et al World Development Report 2007: Development and the Next Generation (2006) 26-28, http://wwwwds.worldbank.org/external/default/WDSContentServer/WDSP/IB/2006/09/13/00 0112742_20060913111024/Rendered/PDF/359990WDR0complete.pdf (accessed 23 October 2016). 
Despite the large number of adolescents in the country, access to quality and affordable sexual health care information and services remains out of reach for those adolescents who need it most. 157 This fact is the result of religious and socio-cultural factors, 158 and is despite the fact that the Nigerian Constitution ${ }^{159}$ guarantees adolescents' rights, including their right to life, 160 dignity, ${ }_{161}$ privacy, $^{162}$ information ${ }^{163}$ and non-discrimination. ${ }^{164}$ All of the aforementioned rights are pivotal in ensuring the protection of adolescent sexual and reproductive health, including their access to contraception, also emergency contraceptives. ${ }^{165}$

157 L Omo-Aghoja 'Sexual and reproductive health: Concepts and current status among Nigerians' (2013) 12 African Journal Medical and Health Sciences 107; $\mathrm{E}$ Monjok et al 'Contraceptive practices in Nigeria: Literature review and recommendation for future policy decisions' (2010) 1 Open Access Journal of Contraception 14; G Sedgh et al Meeting young women's sexual and reproductive health needs in Nigeria (2009) 11, http://www.guttmacher.org/pubs/2009/06/ 03/ASRH_Nigeria.pdf (accessed 14 October 2016) 16.

$158 \mathrm{~T}$ Oloruntoba-Oju 'Young, female and African: Issues in sexual vulnerability' (2011) 7(1) Sexuality in Africa: Magazine and Monographs 3, http://www.arsrc.org/ downloads/sia/jun11/jun11.pdf (accessed 15 October 2013); CO Izugbara 'The socio-cultural context of adolescents' notions of sex and sexuality in rural SouthEastern Nigeria' (2005) 8 Sexualities 607-609; CA Varga 'How gender roles influence sexual and reproductive health among South African adolescents' (2003) 34 Studies in Family Planning 160-172; S Yusuf \& R Booth 'Religious, ethnic, and gender factors affecting sexuality' in RT Francoeur \& RJ Noonan (eds) The continuum complete international encyclopaedia of sexuality (2004) 755-756.

159 The Nigerian Constitution was passed via Decree 24 of 1999. The Constitution is contained in Cap 24 LFN 2004, http://www.nigeria-law.org/Constitution OfTheFederalRepublicOfNigeria.html (accessed 5 October 2016).

$160 \mathrm{Sec} 33$ Nigerian Constitution 1999. The protection of the right to life applies in all circumstances and can be used to hold the government accountable for the loss of life among female adolescents that occurs as a result of their lack of access to vital sexual health information and services including information and services related to emergency contraceptives.

$161 \mathrm{Sec} 34$ Nigerian Constitution 1999. This constitutional provision may be used to ensure that adolescents are treated in a dignified manner, especially when accessing contraceptive (including emergency contraception) information and services in adolescent-friendly facilities.

$162 \mathrm{Sec} 37$ Nigerian Constitution 1999. By guaranteeing this right to everyone, including adolescents, the Constitution provides ample grounds upon which the right of adolescents to access contraceptive services in confidential settings is recognised. In fact, guaranteeing adolescents access to emergency contraception contraceptives in private and confidential environments assists in the maintenance of good sexual health. See Cook et al (n 53 above) 183; Cook \& Dickens (n 53 above) 17; S Jejeebhoy Sexual and reproductive health of young people: Expanding the research and programme agenda (2006) 5, http://hivaidsclearinghouse. unesco.org/search/resources/bie_pop_rev_jejeebhoy.pdf (accessed 15 October 2016).

$163 \mathrm{Sec} 39(1)$ Nigerian Constitution 1999. This right has advanced to the stage that it imposes concrete and immediate obligations on state parties not only to provide access to emergency contraception and other sexual health care services, but also to refrain from interfering with information that is crucial for the promotion and protection of the sexual health choices of adolescents.

164 Sec 42 Nigerian Constitution 1999.

165 It is necessary to point out that the Constitution does not contain any specific provision granting recognition of the protection of the right to health, nor does it guarantee the right to sexual and reproductive health. Health is mentioned only in 
In addition, Nigeria is a party to several international and regional human rights instruments, ${ }^{166}$ and has domesticated the African Charter $^{167}$ which guarantees the right to health in article 16 . This factor makes it possible for courts to rely on the African Charter's provisions in order to ensure that adolescents access emergency contraceptives and other crucial sexual health care services. ${ }^{168}$

Further to the international human rights instruments and constitutional guarantees mentioned above, Nigeria's legislation ${ }^{169}$ and policies ${ }^{170}$ have a direct bearing on adolescent girls' access to emergency contraceptive information and services. The Child Rights Act $^{171}$ mandates that in matters concerning children, their best interests should be the primary consideration with guidance and

sec $17(3)(d)$ under the fundamental objectives and directive principles of state policy that have been declared non-justiciable. See GN Okeke \& C Okeke 'The justiciability of the non-justiciable constitutional policy of governance in Nigeria' (2013) 7 IOSR Journal of Humanities and Social Science 9, http://www. iosrjournals.org/iosr-jhss/papers/Vol7-issue6/B0760914.pdf (accessed 8 October 2016).

166 Nigeria is a signatory to several human rights instruments, such as the ICESCR, ICCPR, CRC, CEDAW, the African Charter, the African Women's Protocol, the African Children's Charter, and so forth. While Nigeria has ratified these instruments, with the exception of the African Charter, they do not have the force of law as they have not been domesticated by the National Assembly which is the legislative arm of government. See sec 12 of the Nigerian Constitution 1999.

167 Adopted in 1981, OAU Doc CAB/LEG/67/3 Rev 5, 21 ILM 58 (1982) and entered into force in October, 1986 http://www1.umn.edu/humanrts/instree/ z1afchar.htm (accessed 20 September 2012). Nigeria ratified the African Charter on 22 June 1983. Nigeria domesticated the contents of the African Charter through the African Charter on Human and Peoples' Rights (Ratification and Enforcement) Act Cap A9, LFN 2004. The power to domesticate international treaties is recognised in sec 315 of the Nigerian Constitution 1999. In Abacha $v$ Fawehinmi (2000) 6 NWLR (Pt 660) 228, the Supreme Court explained that the provisions contained in the African Charter are 'provisions in a class of their own, protected by international law and cannot be overridden by other municipal laws'.

168 In Nigerian cases such as Gbemre $v$ Shell Petroleum Development Company \& Others (2005) Suit FHC/B/CS/53/05 (unreported), http://www.chr.up.ac.za/index.php/ browse-by-subject/418-nigeria-gbemre-v-shell-petroleum-development-companynigeria-limited-and-others-2005-ahrlr-151-nghc-2005.html (accessed 7 March 2013) and Georgina Ahamefule v Imperial Medical Centre \& Alex Molokwu Suit ID/ 1627/2000, http://www.scribd.com/doc/126185950/Georgiana-Ahamefule-vsImperial-Medical-Centre-Dr-Alex-Molokwu-ID-1627-2000-Judgement (accessed 8 March 2013), the courts have consistently held that the violation of the right to health was not only a violation under art 16 of the African Charter, but a violation of the right to life under sec 33 of the Nigerian Constitution. The recent enactment of the National Health Act 2014 also makes the right to health care justiciable for the reason that the National Assembly has enacted a specific law for the protection and enforcement of a Ch 2 provision, namely, health.

169 These include the Child Rights Act (CRA) 2003 and the National Health Act 2014.

170 Policies include the National Health Policy 2004; the National Reproductive Health Policy 2001; the National Policy on Health and Development of Adolescents and Young People 2007; the National Youth Policy 2009; and the Family Life and HIV Education (FLHE) Curriculum.

171 Child Rights Act Cap C50 Laws of the Federation of Nigeria 2004. The Child Rights Act has translated into domestic law provisions for the protection of children's rights already contained in the CRC and its regional counterpart, the African Children's Charter. 
direction provided to them according to their evolving capacities. ${ }^{172}$ With regard to the right of adolescents to sexual health; the Child Rights Act recognises numerous rights, including the rights of children to enjoy the best attainable state of physical, mental and spiritual health; the rights to privacy; the rights to equality; the rights to dignity; and the rights to education, among others. ${ }^{1 / 3}$ The inclusion of these rights in the Child Rights $\mathrm{Act}^{174}$ is to be welcomed, as adolescents not only deserve the adoption of precautionary measures to ensure their survival and socio-economic development, ${ }^{175}$ but they also require adequate access to affordable emergency contraceptives and other sexual health care information and services in a confidential environment with unbiased health care providers in order to allow them to make informed choices about their sexual health.

172 Secs 1, 7(2) \& 277 Child Rights Act. A child is someone under the age of 18 . The definition of the child in the CRA is in line with the definition contained the African Children's Charter, unlike the CRC which, in art 1, defines a child as an individual below the age of 18 years unless, under the law applicable to the child, majority is attained earlier.

173 Secs 8(1), 10, 11, 13 \& 15 Child Rights Act.

174 There is a need for adolescents to be treated with dignity when accessing sexual health care services, especially by health care providers who must be sensitive to their particular needs without exhibiting critical or judgmental attitudes. While the right of adolescents to information is not specifically included in the Child Rights Act, sec 3(1) provides that 'the provisions contained in Chapter IV of the Nigerian Constitution 1999 shall apply as if those provisions are expressly stated in the Act' and, as such, it is felt that adolescents have a right to access important information relating to emergency contraceptives and other sexual health care services as a result of the constitutional provision guaranteeing everyone (adolescents inclusive) the right to information. Major disadvantages of the Child Rights Act, however, include the provision in sec 8(3) which may dissuade adolescents from accessing the required sexual and contraceptive health services, thereby exposing them to numerous risks. Another is that the Child Rights Act does not apply uniformly all over the country due to Nigeria's federal structure which requires the various state legislatures to pass corresponding laws in relation to the protection of children's rights. At present, only 24 states of the Federation have passed corresponding children's rights laws. See UNICEF Nigeria - Fact Sheet on Child Rights Legislation in Nigeria, http://www.unicef.org/nigeria/ Child_rights_legislation_in_Nigeria.pdf (accessed 23 September 2016).

175 International Centre for Research on Women (ICRW) Girls' education, empowerment, and transitions to adulthood: The case for a shared agenda (2012) 8-9, http://www.basiced.org/wp-content/uploads/Publication_Library/ICRW-Girls Education_Empowerment_and_Transitions_to_Adulthood-2013.pdf (accessed 13 October 2016).

176 Nigerian National Health Act 2014, http://www.nphcda.gov.ng/Reports\%20 and\%20Publications/Official\%20Gazette\%20 of\%20the\%20National\%20Health\% 20Act.pdf (accessed 15 September 2016). The Act was passed as law in the country after several controversies had stalled its adoption for almost ten years. See Gl Okowa 'National Health Act: Translating the law into quality and accessible healthcare' (2014) http://www.vanguardngr.com/2015/08/national-health-acttranslating-the-law-into-quality-and-accessible-healthcare/ (accessed 7 October 2016); S Ayo-Aderele 'Rid proposed Health Bill of contentious items - SOs' (2013) http://www.punchng.com/health/rid-proposed-health-bill-of-contentious-itemscsos/ (accessed 21 October 2016); NIMASA 'Nigeria: National Health Bill 2013', 
Recently, the Nigerian National Health Act $^{176}$ was enacted. This Act, aimed at guaranteeing access to basic health care services in the country, provides a framework to be used to periodically effectively monitor, plan, finance and appraise health care services. ${ }^{177}$ Apart from specifically determining that health care providers under no circumstances are to refuse emergency treatment, ${ }^{178}$ the Health Act includes provisions on making accessible to patients relevant information on their health, ${ }^{179}$ and assures that patient privacy and confidentiality are constantly maintained (except in situations where to do so will prove impossible). ${ }^{180}$ Although the Act does not specifically refer to adolescents, adolescents form a part of the larger patient group which it seeks to protect. Thus, the enactment of the Act is a step in the right direction, especially for adolescents who face obstacles when seeking to obtain emergency contraception and other sexual health care information and services at government hospitals, such as a lack of privacy. ${ }^{181}$

In addition to the above, Nigeria has adopted several policies ${ }^{182}$ aimed at promoting adolescent wellbeing and development, and which have a direct influence on their access to sexual health care information and services, including emergency contraceptives in an adolescent-friendly environment. The National Health Policy ${ }^{183}$ provides for a system where health care service delivery is the joint responsibility of the three tiers of government that are primarily responsible for health care services delivery in three (primary, secondary and tertiary) levels in the country. ${ }^{184}$

Local government councils are not merely responsible for the primary health care centres in the various communities with support

I / 0 http://nimsanigeria.wordpress.com/2013/02/13/nigeria-national-health-bill-2013/ (accessed 21 October 2013).

177 See secs 1 and 3(2)(d) of the National Health Act.

178 Sec 20 National Health Act.

179 Sec 23(1) National Health Act.

180 Sec 26 National Health Act.

181 It is felt that the problems faced by adolescents will be relieved specifically by the provisions relating to confidentiality and prohibition of refusal by health officials to provide emergency health care services.

182 The policies include the National Health Policy 2004; the National Reproductive Health Policy 2001; the National Policy on Health and Development of Adolescents and Young People 2007; the National Youth Policy 2009; and the Family Life and HIV Education (FLHE) Curriculum, etc.

183 The 1988 national health policy which was named the National Health Policy and Strategy to Achieve Health for all Nigerians was the first comprehensive health policy in the country.

184 This was the system adopted for the delivery of health care services in Nigeria before independence in 1960. Based upon the guidelines proposed in the Fourth National Development Plan (1981-1985), each local government area would have a minimum of seven primary health centres, 30 health clinics and at least one comprehensive health centre to serve communities of more than 20000 people. See A Scott-Emuakpor 'The evolution of health care systems in Nigeria: Which way forward in the twenty-first century' (2010) 51 Nigerian Medical Journal 53-65 http://www.nigeriamedj.com/article.asp?issn=0300-1652;year=2010; volume=51; issue $=2 ;$ spage $=53$; epage $=65$; aulast $=$ Scott-Emuakpor (accessed 23 October 2016). 
from their respective state ministries of health, but they are also responsible for the provision of the first level of care, immunisations and family-planning services. ${ }^{185}$ Although the three levels of government have the responsibility for a particular level of health care, they are not precluded from providing services in either of the other two levels of care. ${ }^{186}$

Noting that Nigeria's maternal mortality rate is among the highest in the world, the 2004 Health Policy ${ }^{187}$ sets targets that are of relevance to adolescent girls, such as reducing the maternal mortality rate by three-quarters and halting the spread of HIV by 2015.188 Strategies for the achievement of these goals include ensuring capacity building of health care providers and the availability of materials (including emergency contraceptives) necessary for the provision of efficient sexual health care services.

A new National Health Policy was drafted in $2016^{189}$ in order to achieve universal health coverage and other health-related sustainable development goals. The 2016 policy notes that access to primary health care is the fulcrum of the Nigerian health care system and highlights that health care services rendered at these primary health care centres are generally poor and do not instil confidence in the public. This lack is mainly because of fragmented systems for the distribution of medicines, including contraceptives generally and emergency contraceptives in particular. ${ }^{190}$

185 The state government is responsible for the provision of secondary health care services at general hospitals with assistance from respective state ministries of health, while the federal government is responsible for the provision of tertiary health care at teaching hospitals with assistance from the Federal Ministry of Health.

186 MC Asuzu 'The necessity for a health systems reform in Nigeria' (2004) 16 Journal of Community Medicine and Primary Health Care 1; WHO - The Nigerian health system 21-23, http://www.who.int/pmnch/countries/nigeria-plan-chapter-3.pdf (accessed 15 March 2013). The division of responsibility for the delivery of health care services, which includes primary health care services among the three tiers of government, has been maintained in subsequent health policies. It is necessary to point out that while on the face of it, the fact that both the state and federal governments can assist in the provision of services at other levels of care looks good due to a belief that this will lead to the provision of better services, this is not the case as there is often a confusion of roles with a duplication of effort.

187 Nigerian National Health Policy 2004, http://cheld.org/wp-content/uploads/ 2012/04/Nigeria-Revised-National-Health-Policy-2004.pdf (accessed 20 October 2016).

188 Para 3.4 National Health Policy. Other intentions include reducing gender imbalance in SRH matters and promoting the undertaking of comprehensive research on reproductive health issues.

189 National Health Policy 2016 http://nigeriahealthwatch.com/wp-content/uploads/ bsk-pdf-manager/1212_2016_National_Health_Policy_Draft._FMOH_1283.pdf (accessed 24 October 2016).

190 See National Health Policy (n 189 above) 8 \& 12. 
Additional policies of relevance to adolescents' access to emergency contraception in Nigeria are the National Reproductive Health Policy and Strategy ${ }^{191}$ (which provides for actions by the government to ensure adolescents' access to sexual and reproductive health care services including emergency contraceptives); ${ }^{192}$ the Family Life and HIV Education (FLHE) Curriculum, ${ }^{193}$ introduced as a result of the realisation that adolescents are involved in unsafe sexual practices (despite widespread censure of adolescent sexual relations), and the necessity to restructure the existing family life education curriculum in order to allow for sexuality education at the different educational levels in the country. ${ }^{194}$ The aim is to reduce misinformation, to strengthen positive attitudes and to increase adolescents' skills in making informed decisions in relation to their sexual health.

Despite these laudable policies, the main criticism is that the policies are poorly implemented; 19 '5 they are unrealistically 'watered

191 National Reproductive Health Policy (2001) http://www.youth-policy.com/ Policies/Nigeria\%20National\%20Reproductive\%20Health\%20Policy\%20and\%20 Strategy.pdf (accessed 20 October 2016).

192 The actions include the removal of barriers generally affecting access to sexual and reproductive health care services especially at the primary health care level, ensuring the proper training of health care providers and promoting genuine access to family planning information and services. See para 1.3 of the Nigerian National Reproductive Health Policy.

193 Previous population and sexual education programmes that were adopted before 2002 when the Family Life and HIV Education was introduced include the Population Education Programme and the Population Family Life Education Programme. However, it is necessary to state that the two programmes were not successful. See AHI Building consensus for family life and HIV/AIDs education in schools: Report of the national consultative forum with religious leaders on education sector response to adolescent sexual and reproductive health and rights (2004) 4, http://www.actionhealthinc.org/publications/docs/building_consensus.pdf (accessed 24 September 2016).

194 Family Life and HIV Education was initially known as the National Sexuality Education Curriculum. The name and content of the curriculum had to be changed due to concerns from various stakeholders which led the National Council on Education to allow states to implement Family Life and HIV Education in a culturally-acceptable manner, based upon their socio-cultural peculiarities. See National family life and HIV education curriculum for junior secondary schools (2003) I, http://www.actionhealthinc.org/publications/docs/jnrcurriculum.pdf (accessed 17 September 2016); AHI Family life and emerging health issues curriculum: Training guide for colleges of education in Nigeria (2009) iv, http://www.actionhealthinc.org/ publications/docs/FLEHICurriculum-TrainingGuideForCollegesOfEducation2009. pdf (accessed 17 September 2016); A Ajuwon \& W Brieger 'Evaluation of a schoolbased reproductive health education programme in rural South Western Nigeria' (2007) 11 African Journal of Reproductive Health 48.

195 Federal Ministries of Health and Youth Development Action plan for advancing young people's health and development in Nigeria: 2010-2012 (2010) 1 http:// www.health.gov.ng/doc/actionplan.pdf (accessed 22 October 2016); see Lagos State AIDS Control Agency Family life HIV Education implementation: An assessment of the status of implementation of the Family Life HIV Education curriculum in Lagos 
down'; and they merely serve as 'guidelines' for the implementation and provision of health care services and, as such, are not justiciable. ${ }^{196}$

\subsection{Nigerian adolescents' access to emergency contraceptives}

Several reasons have been advanced for the rise in adolescent sexual activity in Nigeria. Some attribute this escalation to the collapse of traditional customary principles, ${ }^{197}$ whereas others are of the view that adolescents engage in sexual activities in order to gain economic benefit. ${ }^{198}$ Kroone asserts that a major explanation for the increase in adolescent sexual relations is the fact that young people marry later in life as they spend many years studying. Nigerian adolescents' adoption of Western ideas and thoughts is also to blame. ${ }^{199}$

In some cases adolescent sexual activities are a result of peer pressure, but in the majority of instances, sexual activity among adolescents occurs due to the desire to satisfy their curiosity and, therefore, are a matter of choice. ${ }^{200}$ More often than not, adolescent girls in Nigeria are victims of sexual violence 201 in most cases perpetrated by persons in positions of trust. ${ }^{202}$ Adolescent sexual

195 State (2012) 6, http://www.google.com.ng/url?sa=t\&rct=j\&q=\&esrc=s\&frm=1\& source $=$ web\&cd $=5 \& \mathrm{cad}=\mathrm{rja} \& \mathrm{ved}=0 \mathrm{CFUQFjAE} \& u \mathrm{rl}=\mathrm{http} \% 3 \mathrm{~A} \% 2 \mathrm{~F} \% 2 \mathrm{Fwww}$.lsaca.o rg\%2Fwp-content\%2Fuploads\%2F2012\%2F06\%2FFLHE-Implementation-Report. doc\&ei=IHcsUvrSCafLOAXopoCoAQ\&usg=AFQjCNFxhTX0g3JIHxKjfvstLrljHjv-nQ\& sig2=hwlHGp5PYXXVNnnmVUWaSw\&bvm=bv.51773540,d.d2k (accessed 18 October 2016).

196 Sedgh et al (n 157 above) 16; AO Esiet Adolescent sexual and reproductive health in Nigeria (2009) http://www.wilsoncenter.org/sites/default/files/Esiet\%20Pres entation.pdf (accessed 17 September 2016).

197 According to these people, the recognition of the individual's autonomy allows for a situation whereby community members can no longer be made accountable for their private sexual decisions. See D Meekers 'Sexual initiation and pre-marital child bearing in sub-Saharan Africa' (1993) 5 Demographic and Health Survey Working Paper 1, http://www.measuredhs.com/pubs/pdf/WP5/WP5.pdf (accessed 24 October 2016).

198 Meekers (n 197 above) 1 \& 2.

$199 \mathrm{MH}$ Kroone Sexual practice of adolescents in Benin (2010) 4, http://www. aktiebenin.nl/userfiles/file/Papers/Sexual\%20practice\%20of\%20adolescents\%20in \%20Benin\%20Engels.pdf (accessed 14 September 2016). See also S Singh \& JE Darroch Adding it up: Costs and benefits of contraceptive services estimates for 2012 (2012) 4 \& 5, http://www.guttmacher.org/pubs/AIU-2012-estimates.pdf (accessed 20 October 2016).

$200 \mathrm{AE}$ Biddlecom et al Protecting the next generation in sub-Saharan Africa: Learning from adolescents to prevent HIV and unintended pregnancy (2007) 13, http:// www.guttmacher.org/pubs/2007/12/12/PNG_monograph.pdf (accessed 27 September 2016).

201 Jewkes (n 42 above) 88; Akanle (n 42 above) 132-138; Family Health International (n 42 above) 3-4; F Akinlusi et al 'Sexual assault in Lagos, Nigeria: A five year retrospective review' (2014) 14 BMC Women's Health http://download. springer.com/static/pdf/290/art\%253A10.1186\%252F1472-6874-14115.pdf?orig inUrl=http\%3A\%2F\%2Fbmcwomenshealth.biomed central.com\%2Farticle\%2F10. $1186 \% 2 \mathrm{~F} 1472-6874-14-115$ \&token $2=\mathrm{exp}=1478294801 \sim$ acl=\%2Fstatic\%2Fpdf\% 2F290\%2Fart\%25253A10.1186\%25252F1472-6874-14-115.pdf* $\sim$ hmac $=4 f 50$ fa9d3b2a8af53bbbda8ee77cdf2691d277710b4049b19e5074805d22fd4d (accessed 27 October 2016). 
relationships often are impromptu ${ }^{203}$ and, consequently, carry the risk of unwanted teenage pregnancies. ${ }^{204}$ This is why knowledge and information about emergency contraceptives and other important sexual health care services are so desperately needed. ${ }^{205}$

In a study on the use of non-conventional methods such as emergency contraception in Nigeria, Ajayi et al discovered that even in situations where adolescent girls were aware of emergency contraception, their rate of utilisation remains low due to misinformation and misconceptions about emergency contraception. 206 The belief that emergency contraception is an abortifacient reveals a major misconception about this contraception among adolescents: a further cause of it not being used. ${ }^{207}$ In fact, due to misinformation, adolescents prefer to use unconventional 'contraceptive' methods as a substitute to using recognised emergency contraceptive pills and resulting in great harm.

It is necessary to emphasise that ensuring Nigerian that adolescents have information about where to access emergency contraceptives is particularly crucial as the termination of unplanned and unwanted pregnancies is illegal in the country, except in situations where the woman's or adolescent girl's life is in danger. ${ }^{208}$ At present, illegal and

202 O Badejoko et al 'Sexual assault in Ile-Ife, Nigeria' (2014) 55 Nigerian Medical Journal 254-259; O Ezechi et al 'Trends and patterns of sexual assaults in Lagos South-Western Nigeria' (2016) 24 Pan African Medical Journal http:// www.panafrican-med-journal.com/content/article/24/261/full/\#.WBzuZ_krLIU (accessed 28 October 2016).

203 J Tripp \& R Viner 'ABC of adolescence: Sexual health, contraception, and teenage pregnancy' (2005) 330 British Medical Journal 590.

204 Teenage pregnancy constitutes a huge problem in Nigeria. The adolescent fertility rate of the country is exceptionally high, especially when compared to the adolescent fertility rates quoted for most countries of the world outside subSaharan Africa. See A Udo et al 'Teenage pregnancy and adverse birth outcomes in Calabar, Nigeria' (2013) 17 Internet Journal of Gynaecology and Obstetrics http:// ispub.com/IJGO/17/2/2995 (accessed 25 October 2016).

205 In the majority of cases, female adolescents either fall pregnant, thereby losing their chances of improving their lives economically. See WHO The sexual and reproductive health of younger adolescents: Research issues in developing countries (2011) 24-25, http://whqlibdoc.who.int/publications/2011/97892415015 52_eng.pdf (accessed 28 October 2016); Udo et al (n 204 above); WHO Adolescent pregnancy http://www.who.int/maternal_child_adolescent/topics/ maternal/adolescent_pregnancy/en/ (accessed 2 November 2016); Galbraith (n 156 above) 253; Ikamari \& Towett (n 155 above) 1-2.

206 A Ajayi et al 'Use of non-emergency contraceptive pills and concoctions as emergency contraception among Nigerian university students: Results of a qualitative study' (2016) 16 BMC Public Health http://bmcpublichealth. biomedcentral.com/articles/10.1186/s12889-016-3707-4 (accessed 28 October 2016).

207 Isa et al (n 143 above) 1393.

208 Nigeria currently has in place highly-restrictive abortion laws that permit access to legal and safe abortion only to save the life of a pregnant woman, thereby leading to a situation where adolescent girls resort to engaging in risky abortion methods, either by adopting various 'traditional methods' or engaging the services of unqualified charlatans. Secs 228-230 Criminal Code Cap c38 LFN 2004 \& secs 232-234 Penal Code cap p3 LFN 2004. See also Bankole et al (n 155 above) 4. 
back street abortions ${ }^{209}$ are major contributors to the high mortality and morbidity rates in the country. ${ }^{210}$

The available data on the sexual and reproductive health outcomes of Nigerian women and adolescents is not encouraging: ${ }^{211}$ The country contributes 10 per cent of the world's maternal deaths. ${ }^{212}$ According to the Demographic and Health Survey of Nigeria, the country not only has a maternal mortality ratio of 576 maternal deaths per 100000 live births, but the lifetime risk of maternal death indicates that one in 30 women in the country will suffer death related to pregnancy or childbearing. ${ }^{213}$ Adolescent girls contribute to Nigeria's high maternal mortality rate as the high rate of unintended pregnancies among the group is a public health crisis (as it is worldwide), 214 and adolescent pregnancy is the main reason for death and ill-health among girls between the ages of 15 and $19 .{ }^{215}$ The consequences mentioned above necessitate that Nigerian adolescents gain wider access to information regarding emergency contraceptives and their use, as well as to information about places or centres where emergency contraceptives and other sexual health care services are available free of charge (or at affordable prices) in the manner envisaged under the African Women's Protocol ${ }^{216}$ and the ICESCR. ${ }^{217}$ Generally, Nigerian adolescents experience the same

209 SA Aderibigbe et al Teenage pregnancy and prevalence of abortion among inschool adolescents in North Central Nigeria' (2011) 7 Asian Social Science 122127; Attahir et al (n 154 above) 15-20; VO Otoide et al 'Why Nigerian adolescents seek abortion rather than contraception: Evidence from focus group discussions' (2001) 27 International Family Planning Perspectives 77-81.

210 K Graczyk Adolescent maternal mortality: An overlooked crisis (2007) http:// www.advocatesforyouth.org/storage/advfy/documents/fsmaternal.pdf (accessed 25 September 2016).

211 National Population Commission and ICF International Nigeria demographic and health survey (2013) 667094 273, http://dhsprogram.com/pubs/pdf/FR293/ FR293.pdf (accessed 27 September 2016); Omo-Aghoja (n 157 above) 106-107.

212 Pathfinder International 'Reproductive health issues in Nigeria: The Islamic perspectives (2004) 9 http://www.nurhitoolkit.org/sites/default/files/tracked_files/ Reproductive\%20Health\%20In\%20Nigeria\%20-\%20Islamic\%20Perspective.pdf (accessed 3 October 2016).

213 National Population Commission \& ICF International (n 211 above) 273.

214 Ramos (n 99 above); WHO (n 205 above).

215 Currently, the country's adolescent birth rate is estimated at 112 per 1000 women aged 15-19 years. See Nigeria - Adolescent fertility rate http:// www.indexmundi.com/facts/nigeria/adolescent-fertility-rate (accessed 10 October 2016.

216 See arts 14(1) (a), (b), (c) and (g) of the African Women's Protocol. The Women's Protocol was adopted by the AU on 11 July 2003 by Resolution AHG/RES.240 $(X X X I)$. It entered into force on 25 November 2005. See also para 8 General Comment 2 of the African Commission on the Protocol to the African Charter on Human and Peoples' Rights on the Rights of Women in Africa http:// www.achpr.org/instruments/general-comment-two-rights-women/ (accessed 2 November 2016).

217 Art 12 ICESCR. See also para 12 of General Comment 14 of the ESCR Committee; both discussed in para 6 below. 
challenges when accessing emergency contraception as their counterparts in the rest of Africa. 218

Similar to the situation those in Nigeria, adolescents in Ethiopia experience poor sexual and reproductive health outcomes as a result of their limited knowledge about sexual health and their limited access to relevant information. This is particularly due to a belief that it is not appropriate to publicly engage in discussions about sexual relations. ${ }^{219}$ However, in order to address these problems, the Ethiopian government recently published several new policies, including the National Adolescent and Youth Reproductive Health Strategy, 220 which specifically address the sexual and reproductive health needs of Ethiopia's young population, as well as the National Comprehensive Reproductive Health Services for Adolescents and Youth Provider Training Curriculum. ${ }^{221}$ These measures were undertaken in order for Ethiopia to align itself with the WHO Guidelines which emphasise the right of young people to privacy, confidentiality and respect when accessing sexual and reproductive health care services, and assuring the provision of comprehensive and integrated sexual and reproductive health services by a nonjudgmental, trained health-care provider. ${ }^{222}$

Understanding that the mere formulation of policies is not sufficient to combat the formidable barriers impeding its adolescents' ability to access sexual and reproductive health services, the Ethiopian government, in partnership with non-governmental organisations (NGOs), also adopted an integrated health care services approach whereby the provision of different health care services is integrated into various youth-friendly sexual and reproductive health care services, including contraception and post-abortion care services in order to maximise adolescents' access to quality health care. ${ }^{223}$

The adoption of the Integrated Family Health Programme in Ethiopia encourages adolescents to visit health facilities where emergency contraception services are offered alongside other, more general health services, thereby reducing the stigma and embarrassment young people experience when accessing sexual health services. The Integrated Family Health Programme notes in its

218 See para 5.2 above.

219 Pathfinder International Youth friendly services: Piloting to scaling-up in Ethiopia (2016) http://www.pathfinder.org/wp-content/uploads/2017/05/Youth-FriendlyServices-Piloting-to-Scaling-up-in-Ethiopia.pdf (accessed 10 September 2017).

220 National Adolescent and Youth Reproductive Health Strategy (2007-2015) http:// countryoffice.unfpa.org/filemanager/files/ethiopia/ayrh_strategy.pdf (accessed 10 September 2017).

221 National Comprehensive Reproductive Health Services for Adolescents and Youth provider training curriculum 2008. See Pathfinder International Youth friendly services (n 219 above) 3.

222 Pathfinder International (n 221 above) 2-3.

223 As above; T Kaneda \& R Naik Integrating health services for young people: Tackling the growing non-communicable disease epidemic (2017) 3-4 http://www.prb.org/ pdf17/NCD\%20Young\%20People\%20Report.pdf (accessed 10 September 2017). 
end-of-programme report that Ethiopia's adoption of adolescent and youth-focused interventions has greatly assisted in increasing access to sexual and reproductive health-related information and services for more than 14 million young persons. ${ }^{224}$

In addition to the measures mentioned above, and acting upon the realisation that religious leaders hold great sway in traditional Ethiopian society, including their giving advice on sexual and reproductive health issues such as family planning, religious leaders were enlisted to incorporate sexual and reproductive health advice in their routine religious messages. ${ }^{225}$

\subsection{Strategic interest litigation as a tool to demand accountability}

It is increasingly being recognised that the courts are an important avenue for attaining higher standards in the enforcement of the sexual and reproductive health rights of girls and women. In fact, national courts often are approached by human rights advocates to assist in bridging the gap between international human rights standards and the reality lived by women. 226

Recognising the importance of adopting a strategic litigation approach, Roa and Klugman ${ }^{227}$ note that strategic litigation ${ }^{228}$ is invaluable in raising awareness - domestically or internationally about various rights, including sexual and reproductive health, as well as the obligation on states to respect, protect, fulfil and promote these rights. This approach is a means of ensuring state accountability as attention is drawn to the plight of the most vulnerable in society who, for several reasons, may not have access to that which is guaranteed in international human rights instruments.

As pointed out above, adolescent girls in Nigeria continue to be vulnerable to sexual and reproductive ill-health, including maternal mortality and morbidity. Their access to emergency contraception and other life-saving sexual and reproductive health services is impeded, despite the country's human rights obligations according to

224 Pathfinder International Integrated Family Health Programme End of Program Report 2008-2016 (2016) 7 \& 18 http://www.pathfinder.org/wp-content/uploads/2017/ 05/IFHP-End-of-Program-Report-2017.pdf (accessed 11 September 2017).

$225 \mathrm{~N}$ Muntean et al 'Addressing the sexual and reproductive health needs of young people in Ethiopia: An analysis of the current situation' (2015) 19 African Journal of Reproductive Health 93.

226 Z Qureshi Using public interest litigation to address maternal mortality and morbidity in Pakistan, https://uclhumanrightsreview.wordpress.com/volume-i/using-publicinterest-litigation-to-address-maternal-mortality-and-morbidity-in-pakistan/ (accessed 7 September 2017).

227 M Roa \& B Klugman 'Considering strategic litigation as an advocacy tool: A case study of the defence of reproductive rights in Colombia' (2014) 22 Reproductive Health Matters 31.

228 Strategic litigation is the litigation of a public interest case that has a broad impact on society - even beyond the specific interests of the parties involved. It has been described as an innovative advocacy tool which serves as a mechanism for demanding accountability from government. 
regional and international instruments, as well as constitutional guarantees of the rights to life, dignity, privacy and access to information. In the case of Nigeria and in the rest of the developing world, therefore, the use of strategic litigation may go a long way towards making governments live up to their responsibilities.

However, it is necessary to point out that the strategic use of litigation is not a new approach as it has in the past been used to hold governments accountable for human rights violations. Such instances include the South African TAC case, ${ }^{229}$ where the government's decision to provide restricted access to Neviropine, an anti-retroviral drug, to pregnant women living with HIV was successfully challenged. Also, in the case of Environmental and Consumer Protection Foundation $v$ Delhi Administration \& Others, ${ }^{230}$ this approach was used to force the Indian government to ensure that schools provide proper facilities, including drinking water and capable teaching staff. In Nigeria, public interest litigation was used in Gbemre $v$ Shell Petroleum Development Company \& Others ${ }^{231}$ to hold the Nigerian government accountable for human rights violations.

The approach of using strategic litigation, therefore, may prove invaluable in demanding accountability from governments on issues relating to the sexual and reproductive health rights of female adolescents, including their lack of access to emergency contraception. In Colombia, for instance, a court overturned a challenge by anti-choice groups to prevent the registration and distribution of emergency contraception on the basis that it was an abortifacient. The Centre for Reproductive Rights and its Colombian partner, Profamilia, submitted an amicus brief in support of the Colombian government's decision to approve the sale and distribution of emergency contraception. The Centre's brief opposed the citizens' petition filed by anti-choice groups in an effort to ban the sale of emergency contraception on the premise that these contraceptives induced abortion and, therefore, were illegal according to Colombian law. Arguing against the petition, the Centre noted that granting the citizens' petition would not only be contrary to the tenets of international human rights law, but would also violate the rights of Colombian girls and women to autonomy in reproductive decision making and their right to access safe and effective contraceptive methods. Deciding against the plaintiffs, the court found that emergency contraception in the form of the morningafter-pill was a contraceptive method and not an abortifacient as argued by the plaintiff, and that access to emergency contraception

229 Minister of Health $v$ Treatment Action Campaign (TAC) 2002 (5) SA 721 (CC).

230 [2012] INSC 584.

231 Gbemre $v$ Shell Petroleum Development Company (n 168 above). 
guaranteed the right to life recognised in the Colombian Constitution. ${ }^{232}$

Also, in a recent decision in Chile the Constitutional Tribunal lifted the total abortion ban that had been in place for 28 years, to decriminalise abortion in cases of rape, foetal impairment or when a woman's life is in danger. The Centre for Reproductive Rights in partnership with other civil organisations had not only submitted an amicus brief demonstrating that the review was in line with international standards, but also testified before the Tribunal in support of the Abortion Bill meant to replace the existing draconian law which resulted in about 200000 unsafe abortions per year. ${ }^{233}$

Below we turn to an examination of General Comments of selected treaty-monitoring bodies in order to arrive at insights regarding the protection of adolescents' rights to access emergency contraception.

\section{Insights gained from selected comments of treaty- monitoring bodies}

\subsection{Introduction}

Treaty-monitoring bodies monitor the fulfilment by state parties of the obligations created by human rights instruments. Treaty-monitoring bodies use General Comments or general recommendations as tools to aid in the interpretation and development of the provisions of international human rights instruments in order to guide states that are parties to those instruments in the implementation of their obligations.

\subsection{African Commission on Human and Peoples' Rights}

The African Commission on Human and Peoples' Rights (African Commission) adopted General Comment 2 on articles 14(1)(a), (b), (c) and (f) and articles 14(2)(a) and (c) of the Protocol to the African Charter on Human and Peoples' Rights on the Rights of Women in Africa (African Women's Protocol) at its 55th ordinary session.234 General Comment 2 provides interpretive guidance on the overall and specific obligations of state parties towards promoting the effective

232 See Council of State of the Republic of Colombia (2002) judgment of 5 June 2008, Exp 11001-03- 24-000-2002-00251-01, Bulletin 25, June 16/08: para 2.2.2, cited in E Kismodi et al 'Advancing sexual health through human rights: The role of the law' (2015) 10 Global Public Health 259. See also CRR In re Access to Emergency Contraception in Colombia (amicus brief) (Colombian Council of State) (2008) https://www.reproductiverights.org/case/in-re-access-to-emergencycontraception-in-colombia-amicus-brief-colombian-council-of-state (accessed 5 September 2017).

233 CRR Chile makes history (2017) https://www.reproductiverights.org/feature/chilemakes-history (accessed 12 September 2017).

234 Held from 28 April-12 May 2014 in Luanda, Angola. 
domestication and implementation of article 14 of the African Women's Protocol.

The relevance of General Comment 2 in the quest to ensure adolescents' access to emergency contraceptives cannot be overemphasised. Under the heading 'Access to sexual and reproductive health services', paragraph 29 of General Comment 2 cautions that ensuring the availability, accessibility and acceptability of quality sexual and reproductive health care services for women is crucial and that, consequently, states have the obligation to ensure 'comprehensive, integrated, rights-based, women-centred and youthfriendly services that are free of coercion, discrimination and violence'. The African Commission clearly is aware that adolescents face significant obstacles related to a lack of youth-friendly health care centres, and that this is preventing them from realising their rights to access emergency contraception.

Also, in paragraph 30 of General Comment 2 the African Commission stresses the importance of choice in contraceptive methods, highlighting the Commission's concern 'about the limitations on and insufficient access to women's sexual and reproductive health services including access to preventive choices and methods'. This of course includes access by women and adolescent girls to emergency contraceptives.

Paragraph 31 of General Comment 2 is of particular relevance in light of the obstacles placed in the way of adolescents accessing these services by misguided health care workers, as discussed above. ${ }^{235}$ The African Commission cautions that states should 'ensure that health workers are not allowed, on the basis of religion or conscience, to deny access to sexual and reproductive health services to women as highlighted in this document'. We have highlighted above that one of the obstacles in the way of adolescents' access to emergency contraceptives involves the use of 'conscience' clauses which allows health care providers (and pharmacists) to refuse to provide emergency contraception pills and other contraceptive methods to adolescents and women, because of their religious inclinations, significantly affecting their ability to access emergency contraceptives within the time frame when they are most effective. Paragraph 31 of General Comment 2, therefore, places a positive obligation upon states to ensure that health care providers are prevented from limiting access to emergency contraception in this way.

Finally, paragraph 46 of General Comment 2 entreats states to take 'all appropriate measures, through policies, programmes and awareness-raising in order to eliminate all barriers to women and girls enjoyment of sexual and reproductive health'. Paragraph 46 further notes that states should work towards eliminating 'disparities, harmful traditional and cultural practices, patriarchal attitudes, discriminatory

235 See para 5.1 above. 
laws and policies in accordance with articles 2 and 5 of the Protocol'. The importance of paragraph 46 in reiterating the obligation put on states that are parties to the African Women's Protocol to ensure access to emergency contraception is self-evident, namely, that policies, procedures, practices and socio-cultural attitudes impeding access to emergency contraception should be eliminated.

\subsection{African Committee of Experts on the Rights and Welfare of the Child}

The right to the highest attainable standard of health requires African governments to ensure that its four essentials elements - availability, accessibility, acceptability and quality ${ }^{236}$ - are achieved in the region without discrimination based on age. ${ }^{237}$ In order to ensure that the provisions of the African Children's Charter are effectively implemented in the region, the African Committee of Experts on the Rights and Welfare of the Child (African Children's Committee) was established. $^{238}$ The Children's Committee has the mandate to monitor the implementation and protection of the rights of the child in Africa and, in order to do this, receives and considers state reports, individual communications pertaining to infringement of the rights of the child as contained in the African Children's Charter, and undertakes country investigations on issues relating to the violation of the rights of children in member states. ${ }^{239}$

In line with its authority to receive communications from individuals and groups about violations of children's rights, the African Children's Committee received a communication against the government of Kenya on behalf of children of Nubian descent in Kenya. This followed unsuccessful attempts by the Nubian community to affirm their rights to Kenyan nationality in the Kenyan national courts. ${ }^{240}$ Based on the recognition in article 6 of the African Children's Charter of the rights

236 Para 12 General Comment 14 of the ESCR Committee. This involves facilities, drugs and health providers being available and accessible in sufficient quantities without discrimination. Also, quality SRH care services must be rendered by medical personnel that are skilled in their field and, most importantly, the services should be rendered in a manner that is not only culturally appropriate but must seek to protect the confidentiality of its clients, adolescents, at all times except where it will be improper to do so.

237 See paras 18-19 of General Comment 14 of the ESCR Committee.

238 The African Children's Committee was created in July 2001 during the 37th session of the Assembly of Heads of State and Government of the African Union in Lusaka, Zambia. It is a body of 11 independent experts who have been given the primary responsibility of overseeing the protection of the rights of children in the region. See arts $32 \& 33$ of the African Children's Charter.

239 See generally arts $42-45$ of the African Children's Charter on the mandate and procedure of the Children's Committee.

240 Institute for Human Rights and Development in Africa (IHRDA) and Open Society Justice Initiative on behalf of Children of Nubian Descent in Kenya $v$ The Government of Kenya Communication Com/002/2009, http://www.ihrda.org/wp-content/ uploads/2011/09/002-09-Nubian-children-v-Kenya-Eng.pdf (accessed 27 June 2016). 
of children to nationality, 241 it was argued that the Kenyan government's stance in denying this right caused various violations of children's rights, such as a violation of their right to education, health care services and non-discrimination. ${ }^{242}$ After considering various presentations made to it, the African Children's Committee held Kenya to be in violation of the various articles as alleged. ${ }^{243}$

As it did in the Nubian Children case, the Children's Committee is able specifically to make declarations that relate to adolescents' access to emergency contraception and other sexual health care services. In a recent Declaration on Ending Child Marriage in Africa, the Children's Committee expressed the view that child marriages adversely affected the health and well-being of the girl child, and called upon stake-holders to address the structural causes of child marriages and promote access to sexual health information, education and services. 244

In line with its mandate to ensure the rights of African children recognised in the African Children's Charter, the African Children's Committee potentially is able to ensure the development of a robust jurisprudence that can assist in the advancement of children's rights. ${ }^{245}$ Also, in line with its mandate to interpret the provisions of the African Children's Charter, through General Comments the Children's Committee can issue authoritative interpretations of the provisions contained in the African Children's Charter to clarify their meaning and scope. ${ }^{246}$

At present the Children's Committee has issued only two General Comments: one dealing with the rights of children of incarcerated mothers, ${ }^{247}$ and another dealing with children's rights to birth registration, name and nationality. ${ }^{248}$ The African Children's Committee is yet to issue a General Comment on adolescents' access

241 See para 7 Nubian Children case (n 240 above).

242 As above.

243 See generally paras 37-68 Nubian Children case (n 240 above).

244 African Children's Committee The Addis Ababa Declaration on ending child marriage in Africa was made at the 23rd session of the African Committee of Experts on the Rights and Welfare of the Child held in Addis Ababa, Ethiopia, in April 2014, http://srsg.violenceagainstchildren.org/sites/default/files/documents/ docs/ACERWC-Declaration-on-Ending-Child-Marriage-in-Africa.pdf (accessed 27 June 2016); African Committee of Experts Concept note on the Day of the African Child 2015 (2015) 4, http://www.girlsnotbrides.org/wp-content/uploads/ 2015/06/Concept-Note-DAC-2015.pdf (accessed 27 June 2016).

245 E Durojaye 'The potential of the Expert Committee of the African Children's Charter in advancing adolescent sexual health and rights in Africa' (2013) 46 Comparative and International Law Journal of Southern Africa 401.

246 African Children's Charter General Comments http://www.acerwc.org/generalcomments/ (accessed 25 June 2016).

247 General Comment 1 of the African Children's Committee issued in 2013, http:// www.acerwc.org/download/general_comment_on_article_30_of_the_acrwc_eng lish/?wpdmdl=8597 (accessed 27 June 2016).

248 General Comment 2 of the African Children's Committee http://www.acerwc.org/ download/general_comment_article_6_name_and_nationality/?wpdmdl=8606 (accessed 27 June $\mathbf{2 0 1 6 ) .}$ 
to sexual and reproductive rights and health. It is recommended that this should be done as soon as possible in the same way as has been done by its UN-based counterpart - the CRC Committee - which consistently gives purposeful interpretation to the provisions of the CRC that lends substance to provisions of the Convention.

As noted above, ${ }^{249}$ a major obstacle to adolescents' access to emergency contraception is the lack of available information on the contraceptives and their use. Also, the blocking of access to sexual health care services by religious and societal gate-keepers who rely on the limitation in article 7 of the African Children's Charter ${ }^{250}$ to restrict adolescents' access to sexual health care information and services violates their right to health care. The limitation in article 7 makes the right subject to 'such restrictions as are prescribed by laws', thus restricting adolescents' rights to access available information, to express their opinions freely, and to disseminate their opinions subject to whatever restrictive laws are in place in the particular state. This limitation, therefore, enables states to hide behind restrictive national laws that inculcate religious and cultural taboos on children's access to sexual and reproductive health information and services, including information and services regarding emergency contraception, and so enables states to limit adolescents' rights.

To resolve these obstacles, we recommend that the African Children's Committee should provide a decisive interpretation of the African Children's Charter, stating clearly that despite the 'restriction' contained in article 7, the rights of children to enjoy the best attainable state of physical, mental and spiritual health ${ }^{251}$ includes their rights to access available and affordable quality sexual healthcare information and services. Article 7 , instead, should be read as an attempt to empower adolescents to make their own decisions in the face of parental or societal opposition. Moreover, in all cases the best interests and evolving capacities ${ }^{252}$ of the adolescent should be considered.

Since another impediment affecting adolescent girls' access to emergency contraception and other sexual health care services is the absence of privacy and confidentiality in accessing emergency contraception, ${ }^{253}$ the African Children's Committee needs specifically to impress upon African governments the necessity of not only of enacting laws on adolescents' access to confidential sexual and

249 Hooja \& Mital (n 140 above); Babatunde et al (n 32 above) 23.

250 Art 7 of the African Children's Charter provides that '[e]very child who is capable of communicating his or her own views shall be assured the rights to express his opinions freely in all matters and to disseminate his opinions subject to such restrictions as are prescribed by laws'.

251 Art 14(1) African Children's Charter.

252 The best interests of the child are recognised in art 4 of the African Children's Charter.

253 Family Health International (n 83 above) 7. See also Hooja \& Mital (n 140 above) 16. 
reproductive health care services, ${ }^{254}$ but also of monitoring the implementation of these laws so that genuine access to emergency contraceptives and other regular contraceptives may be achieved. ${ }^{255}$

In line with its mandate to examine state reports, the African Children's Committee should look into the reports submitted to it and, in its Concluding Recommendations, should hold African governments accountable for the various violations of the sexual health rights of adolescents., This it should do while also making comments that may assist in advancing adolescents' sexual and reproductive health needs, especially their access to emergency and other contraception, as inaccessible contraception is responsible for the region's continuing high rates of unplanned adolescent pregnancies and mortality resulting from unsafe abortions.

\subsection{Committee on the Convention on the Rights of the Child}

Noting that state parties have neglected the protection of the rights of adolescents in their access to sexual health information and services, thereby exposing them to sexual ill-health, the CRC Committee issued General Comments $3^{256}$ and $4 .^{257}$ It did this in order to provide guidance to state parties to advance the realisation of the health rights of adolescents. In General Comment 4, the CRC Committee urged African states to remove barriers that hinder adolescents' access to sexual and reproductive health information. 258 The CRC Committee stated that denying adolescents in the African region access to emergency contraceptives on the grounds of their age infringes their rights to non-discrimination as guaranteed in article 3 of the African Children's Charter. Specifically, the CRC Committee categorically explained, in particular, that denying adolescent girls access to sexual health care services was an infringement of their various rights as it puts at risk and limits their developmental potential. ${ }^{259}$

In a General Comment on the Best Interests of Children, ${ }^{260}$ the CRC Committee identified this principle as one of four general

254 Para 24 of General Comment 3 of the CRC Committee; para 29 of General Comment 4 of the CRC Committee.

255 Concluding Observation of the CRC Committee to Nicaragua 1999 CRC/C/15/ Add. 108, http://www.unhchr.ch/tbs/doc.nsf/(Symbol)/a60af0697af8394280256 79700483778? Opendocument. (accessed 25 October 2015).

256 General Comment 3 on HIV/AIDS and the rights of the child issued at its 32 nd session in 2003.

257 General Comment 4 on adolescent health and development in the context of the Convention on the Rights of the Child issued at its 33rd session (2003).

258 Paras $24 \& 26$ of General Comment 4 of the CRC Committee.

259 Para 6 of General Comment 4 of the CRC Committee.

260 General Comment 14 on the right of the child to have his or her best interests taken as a primary consideration issued at its 62nd session (2014). 
principles $^{261}$ that are important for interpreting and implementing children's rights. ${ }^{262}$ In pointing out that the judgment of adults on what is believed to be in a child's best interests should not impede the duty to respect children's rights, it explains that all the rights protected in the CRC are in the child's best interests and that none should be interpreted negatively. ${ }^{263}$ Aligning ourselves with Durojaye's view, ${ }^{264}$ we recommend that a purposeful analysis of the provision on parental responsibilities contained in the African Children's Charter ${ }^{265}$ should explicitly include an obligation on parents to ensure that their wards receive important sexuality information and education as this is in their best interests. The acceptance of this obligation should go a long way towards improving adolescents' access to emergency contraceptives, particularly, and other sexual health care services, generally.

Furthermore, in relation to children's rights to the enjoyment of the highest attainable standard of health, in General Comment $15^{266}$ the CRC Committee noted that the right to health is made up of freedoms and entitlements. ${ }^{267}$ While entitlements grant children the right to access sexual and reproductive health care services that will enable them to enjoy the highest attainable standard of health, freedoms (that progressively increase in line with their maturity and

261 Other principles include the obligation on states to respect and ensure the rights of the child to non-discrimination in art 2; the right of the child to life, survival and development in art 6; and the right of the child to be heard and to express his or her views freely in 'all matters affecting the child' in art 12. See generally para 12 of General Comment 5 of the CRC Committee's (2003) and para 2 of General Comment 12 of the CRC Committee (2009) http://www.refworld.org/ docid/4ae562c52.html (accessed 4 June 2014).

262 Para 1 of General Comment 14 of the CRC Committee.

263 The 'best interests' principle recognises children as vulnerable members of society who deserve the highest levels of protection. The principle has been interpreted to mean the careful deliberation by state parties and other stakeholders (including judges) in their actions and orders as to what best serves the interests of children in all situations. Ensuring that adolescents have access to comprehensive SRH information has been adjudged as being in their best interests. According to the Committee, its reason for developing the General Comment is based on the need to strengthen an understanding and application of the right of children to have their best interests assessed and taken as a primary consideration in order to engineer a 'real change' in attitude that will lead to the full respect of children as rights holders. See generally paras 4,11 and 12 of General comment 14 of the CRC Committee. See also G Lansdown \& M Wernham 'Are protection and autonomy opposing concepts?' in IPPF (ed) Understanding young people's right to decide (2012) http://www.ippf.org/sites/default/files/ippf_right_to_decide_03.pdf (accessed 12 June 2016).

264 Durojaye (n 245 above) 398.

265 Art 20 African Children's Charter.

266 Children's rights to health are internationally protected in art 24 of the CRC General Comment 15 on right of the child to the enjoyment of the highest attainable standard of health issued by the CRC Committee in 2013 (CRC/C/GC) 15).

267 Para 24 of General Comment 15 of the CRC Committee. 
evolving capacity) include their autonomy to make responsible sexual and reproductive health choices. 268

It is also necessary to point out that the realisation of adolescents' sexual health rights in the African region to a large extent rests on their being able to access confidential consultations with health providers who should ascertain whether they are Gillick-competent. Consequently, in considering the evolving capacities of children as recognised in the African Children's Charter, ${ }^{269}$ the CRC Committee has advised governments to ensure that health care professionals specifically employed to render sexual health services to adolescents respect their rights to privacy. ${ }^{270}$

\subsection{UN Committee on Economic, Social and Cultural Rights}

We conclude this section of the article by briefly turning our attention to General Comments 14 and 22 of the UN Committee on Economic, Social and Cultural Rights (ESCR Committee) on the right to health. ${ }^{271}$ In General Comment 14, the ESCR Committee notes that the right to health is an inclusive right that extends to 'the underlying determinants of health', such as 'access to health-related education and information, including on sexual and reproductive health'. ${ }^{272}$ By stressing the importance of education and information on sexual and reproductive health as an underlying determinant of health, the ESCR Committee displays its awareness that health cannot be achieved without adequate educational and information programmes being in place. As was pointed out above, ${ }^{273}$ in the case of emergency contraception education and information about the method of contraception are severely lacking. General Comment 14, therefore, may be considered a call to action for states to include emergency contraception in health education and information programmes. The ESCR Committee further notes that health care services, including reproductive health care, must be available, accessible, acceptable and of good quality to all, particularly to vulnerable and marginalised groups such as young persons, ${ }^{274}$ highlighting the extremely

268 As above.

269 Art 9(2) African Children's Charter and art 5 of the CRC.

270 Para 17 of General Comment 3 of the CRC Committee.

271 ESCR Committee General Comment 14: The Right to the Highest Attainable Standard of Health, 22nd session, 25 April-12 May 2000, Supp 2, UN Doc E/C.12/ 2000/4, 9, 11 (2000), http://www.ohchr.org/Documents/Issues/Women/WRGS/ Health/GC14.pdf (accessed 22 October 2016); General Comment 22: The right to sexual and reproductive health (2016) UN Doc E/C.12/GC/22 https://www.escrnet.org/resources/general-comment-no-22-2016-right-sexual-and-reproductivehealth (accessed 12 September 2017). The ESCR Committee was created in 1985 as a subsidiary of the Economic and Social Council of the UN and is vested with the mandate of performing monitoring functions over the ICESCR, and state parties are to submit periodic reports on the measures adopted and progress achieved in implementing the right contained in the Covenant.

272 Para 11 General Comment 14.

273 Para 5.2 above.

274 Para 12 General Comment 14. 
vulnerable status of adolescents when accessing reproductive health care services, including emergency contraception.

In General Comment 14, the ESCR Committee introduces minimum core essentials to be guaranteed by state parties to the Covenant. $^{275}$ Pertaining to the right to health, essentials to be guaranteed by state parties include availability, accessibility, acceptability and quality. ${ }^{276}$ In the context of adolescents' access to emergency contraception, 'availability' entails not only that health care facilities stock emergency contraception pills but also that the health care personnel at these facilities are fully trained in their use and are willing to prescribe this contraceptive. Also, emergency contraception must be available in sufficient quantities in both public and private health care facilities and within reasonable geographical reach.

'Accessibility' entails that health facilities are physically and economically accessible without discrimination to all adolescent girls needing emergency contraception and without distinction between those living in rural and urban areas. It also includes informational accessibility which means that adolescents who need to access the services must receive or have access to all requisite information pertaining to the treatment or service, including emergency contraception.

'Acceptability' entails that health care services and the facilities provided must be acceptable in terms of medical ethics, be culturally appropriate and must respect the rights to confidentiality of the adolescents they serve. This demand is particularly important if we note that one of the most significant barriers to adolescents accessing emergency contraception is a lack of confidentiality: General Comment 14, therefore, stresses the need to respect adolescents' rights to confidentiality when accessing emergency contraception.

'Quality' entails that all the facilities and services rendered must be of good quality and the medical personnel must be skilled in their various fields. It is submitted that this essentially includes when and how to prescribe emergency contraceptives to adolescents.

The observance of the core minimum content in relation to female adolescents' access to emergency contraceptive information and

275 As above. The South African Constitutional Court has consistently refused to engage with the concept of a minimum core content in its jurisprudence, and instead has opted for an approach of 'reasonableness'. For a critique of the approach of the Court, see D Bilchitz 'Giving socio-economic rights teeth: The minimum core and its importance' (2002) 119 South African Law Journal 484-501; D Bilchitz 'Towards a reasonable approach to the minimum core: Laying the foundations for future socio-economic rights jurisprudence' (2003) 19 South African Journal on Human Rights 1-26; D Brand 'Judicial deference and democracy in socio-economic rights cases in South Africa' (2011) 3 Stellenbosch Law Review 614-638; and S Liebenberg Socio-economic rights: Adjudicating under a transformative constitution (2010) 131-227.

276 As above. 
services requires that state parties establish sufficient adolescentfriendly clinics in both rural and urban areas; ${ }^{277}$ employ health providers with positive attitudes; ${ }^{278}$ introduce comprehensive sexual and family life education in schools; ${ }^{279}$ enact laws that proscribe stereotypes and discrimination; and ensure that the confidentiality and privacy of adolescent patients are maintained when accessing contraceptive services except where it will not be in the child's best interests, among others.

In line with the ESCR Committee's interpretation in its General Comment $14,{ }^{280}$ the rights of female adolescents to access contraception are violated ${ }^{281}$ where state parties adopt policies and laws that bar them from accessing necessary information on the availability of contraceptive services and other reproductive health services. Also, state parties violate the right to health where their agents deliberately withhold information from adolescent girls that the use of family planning assists in the prevention of teenage pregnancies and infection by STIs, or where their accessibility to contraceptives is impeded due to the privatisation of health care services without providing alternatives where required information and services may be obtained. ${ }^{282}$

Paragraph 14 of General Comment 14 stresses that the right in article 12 of the Covenant may be 'understood as requiring measures to improve child and maternal health, sexual and reproductive health services, including access to family planning', underscoring the obligation on states to provide measures to improve access to sexual and reproductive health services, including emergency contraception.

The ESCR Committee further stresses that parties to the ICESCR should provide 'a safe and supportive environment for adolescents', in order to ensure that they have the 'opportunity to participate in

277 In its Concluding Observations to Russia in 2011, the ESCR Committee recommended ensuring that the Russian government should ensure that family planning information and services are available to everyone, including people residing in the rural areas, and that the teaching of sex education to adolescents should be included in the school curricular so as to prevent early pregnancy and STIs. See para 30 of the ESCR Committee's Concluding Observations on Russia $2011 \mathrm{E} / \mathrm{C} .12 / \mathrm{RUS} / \mathrm{CO} / 5$.

278 'Positive attitude' here means health providers who do not have issues with prescribing contraception or other reproductive health services to adolescent girls.

279 In its Concluding Observations to the Republic of Moldova in 2011, the ESCR Committee expressed concern at the withdrawal of the teaching of life skills courses in public schools, and recommended that the teaching of sexual and reproductive rights should be reintroduced in the curricula of schools. See para 27 of the ESCR Committee's Concluding Observation on Moldova E/C.12/MDA/CO/ 2.

280 Paras 47-52 of General Comment 14 of the ESCR Committee.

281 A violation occurs where a state party is unwilling to invest the maximum available resources to ensure the realisation of the right to health in fulfilment of its obligations under article 12. In cases where a violation results from of an inability to comply, it is mandatory that the state party justify that it has expediently invested all available resources to satisfy its obligations.

282 Para 35 of General Comment 14. 
decisions affecting their health, to build life skills, to acquire appropriate information, to receive counselling and to negotiate the health behaviour choices they make'. The significance of this directive for the provisioning of emergency contraception is self-evident.

The ESCR Committee also stresses that the rights to health of adolescents are 'dependent on the development of youth-friendly health care, which respects confidentiality and privacy and includes appropriate sexual and reproductive health services' ${ }^{283}$ We would argue that 'appropriate sexual and reproductive health services' include access to emergency contraception in a youth-friendly setting that respects the adolescent's privacy and confidentiality.

In General Comment 22, the ESCR Committee explains that the right to sexual and reproductive health is an integral part of the general right to health and primarily is linked to and is interdependent with the enjoyment of other rights, including the rights to life, education and information, equality and privacy. ${ }^{284}$ Noting that the sexual and reproductive health of individuals is deeply affected by social determinants that generally reflect existing societal inequalities and limit the choices women and adolescent girls can make with respect to their sexual and reproductive health, the ESCR Committee reiterates the need for state parties to address the social determinants as manifested in their laws and social practices which prevent women from effectively enjoying their sexual and reproductive health in practice. $^{285}$

According to the ESCR Committee, as a result of women's reproductive capacities, the guarantee of the right to sexual and reproductive health is not only essential to the realisation of the full range of their (other) rights, but also indispensable to their rights to make meaningful decisions about their health. To achieve equality, there is a need to understand that achieving gender equality requires that the health needs of women and girls, different from those of men, be taken into account with appropriate services provided to them throughout their lifetime. ${ }^{286}$

Thus, bearing the above in mind, there is a need for African governments not only to dismantle all forms of direct and indirect discrimination that persist in seemingly neutral laws, policies and practices which hinder women and adolescent girls from making autonomous decisions and accessing sexual and reproductive health information and services, but also to remove the inherent disadvantages women experience when exercising their rights to sexual and reproductive health. ${ }^{287}$ These goals can be achieved by specifically adopting, reviewing and consistently implementing

283 Para 23 of General Comment 14.

284 Paras 1, $5,9 \& 10$ of General Comment 22.

285 Para 8 of General Comment 22.

286 Para 25 of General Comment 22.

287 Paras $26 \& 27$ of General Comment 22. 
measures that will assure access to comprehensive sexual and reproductive health services, education and information in order to prevent unintended pregnancies and unsafe abortions. These measures include lowering the rates of maternal mortality and morbidity through access by women and girls to emergency obstetric care, skilled birth attendance in both rural and urban areas, as well as guaranteeing to all women and girls access to affordable, safe and effective contraceptives and quality post-abortion care where required. 288

\subsection{CEDAW Committee}

The Committee monitoring the implementation by state parties of CEDAW, the Committee on the Elimination of all Forms of Discrimination Against Women (CEDAW Committee), has issued several General Comments and recommendations addressing women's and girls' health issues, including General Recommendation 24 which specifically deals with women and health. 289

General Recommendation 24 declares that the issues of 'HIV/AIDS and other sexually-transmitted diseases are central to the rights of women and adolescent girls to sexual health'.290 Importantly, the General Recommendation notes that women and girls suffer from a lack of adequate information and of services; that they do not have sufficient power to refuse sex or insist on safe sexual practices; and that they often are subjected to marital rape and polygamy, exposing them to HIV infection. ${ }^{291}$ From the evidence presented in the paragraphs above, ${ }^{292}$ it is evident that this lack of adequate information includes information on emergency contraception, and that such knowledge may help protect against the consequences of unsafe sexual practices.

General Recommendation 24 further compels states to ensure the right to sexual health information for all women and girls, especially sex workers and trafficked women and girls, in programmes designed to respect their rights to privacy and confidentiality. ${ }^{293}$ This underscores our argument that such information must include

288 Paras $28 \& 49$ of General Comment 22.

289 Committee on the Elimination of Discrimination against Women General Recommendation 24 Women and Health, http://www.unhchr.ch/tbs/doc.nsf/ (Symbol)/77bae3190a903f8d80256785005599f (accessed 1 September 2017). Note that the CEDAW Committee has not yet dealt with the issue of discrimination against women or girls in accessing emergency contraception. The only communication so far dealing with women's and girls' access to health care services is AS $v$ Hungary (Communication 4/2004), in which the author alleged a contravention by the state party of arts 10(h), 12 and 16(1)(e) of CEDAW, in that she was forced to undergo forced sterilisation when accessing a state hospital for an emergency cesarean section to remove her dead foetus.

290 Para 18.

291 As above.

292 See paras $5 \& 6$ above.

293 Para 18. 
information on emergency contraception. The privacy and confidentiality of adolescents accessing emergency contraception services must be guaranteed, in line with this Recommendation. ${ }^{294}$

\section{Recommendations on the way forward}

As previously argued, adolescent girls' inability to access information about available means to protect themselves from unplanned and unwanted pregnancies leads to disastrous consequences for them and for society. ${ }^{295}$ Therefore, in order to increase the health benefits associated with the widespread use of emergency contraception, it is necessary that adolescent girls are adequately informed and educated about the existence and use of this type of contraception. More importantly, it is paramount that adolescents are made aware of the time frames within which emergency contraceptives are effective.

In order to improve adolescents' access to emergency contraception, emergency contraceptives must be made as easily accessible as possible. Efforts should be made to ensure their availability in state health care institutions, private pharmacies and, especially, in adolescent-friendly health establishments.

In keeping with General Comment 2 of the African Commission, steps should be taken to remove societal and religious barriers that impede access to emergency contraception. This may be done by organising awareness-raising campaigns in the various information media to effect attitudinal changes to contraceptive use by adolescents, generally, and to emergency contraception, in particular. To achieve this, community and religious leaders need to be convinced of the need to encourage adolescents to use emergency contraceptives, especially in situations of sexual violence and assault. This may be done through presenting them with factual evidence on the negative effects occasioned by unplanned and unwanted pregnancies and the procurement of unsafe abortions, or by following the approach taken in Ethiopia where religious leaders are co-opted into incorporating important sexual and reproductive health information in their routine religious messages. ${ }^{296}$

To overcome concerns about the infringement of adolescents' privacy and confidentiality, it is necessary that sufficient adolescentfriendly health centres which operate during adolescent-friendly hours are established. These centres should be manned by approachable health care providers and should not be too far from where adolescents live. These centres should also be able to provide

294 See para 7 below. For additional insights into the jurisprudence of the CEDAW Committee as it is relevant to African women's and girls' reproductive rights, see $S$ lyayi Ibadin 'A critical evaluation of CEDAW Committee jurisprudence and its relevance to African women' LLM dissertation, University of Pretoria, 2011.

295 Hoque \& Ghuman (n 91 above) 2.

296 Muntean et al (n 225 above) 93. 
educational and other interactive programmes in addition to sexual health care services. The adoption of these measures will assist in rapidly reducing the embarrassment adolescents experience when asking a health care provider to prescribe emergency contraceptives.

It is in the best interests of adolescents that they are actively involved in decision-making processes on issues relating to the protection of their sexual health. Therefore, it is necessary that African governments ensure that adolescents are co-opted and encouraged to participate in programmes on emergency contraception intended for their benefit. Adolescents should be empowered so that they may avoid the health risks attendant upon a failure to access emergency contraception. The use of health-promoting strategies as a framework should be adopted to achieve this. Such strategies include building personal skills; creating a supportive environment; strengthening community action; reorienting health and social services; and instituting healthy public policies. 297

\section{Conclusion}

We have argued that as governments have committed themselves at international human rights fora to prioritising adolescents' development and wellbeing, particularly their educational and health needs, governments should adopt programmes which promote adolescents' education about and access to emergency contraception. These programmes should be aimed at enabling adolescents to deal in a positive manner with their awakening sexuality. African adolescents should be able freely to access sexual health care information and services, including those relating to emergency contraception.

We highlight the challenges currently faced by adolescents in subSaharan Africa when attempting to access emergency contraception, as well as the numerous sexual and reproductive health hazards resulting from their inability to access these services. These hazards are unintended pregnancies, unsafe abortions, and sexually-transmitted infections, to name but a few.

Additionally we indicate the potentially valuable role to be played on the African continent by the African Committee of Experts on the Rights and Welfare of the Child. We argue that a proactive interpretation of the rights in the African Children's Charter by the African Children's Committee may go a long way towards respecting, protecting and fulfilling adolescents' rights of access to emergency contraception. Such an interpretation was presented by the UN

297 S Kumar and GS Preetha 'Health promotion: An effective tool for global health' (2012) 37 Indian Journal of Community Medicine 5-12; Health Service Executive The health promotion strategic framework http://www.healthpromotion.ie/hp-files/ docs/HPSF_HSE.pdf (accessed 28 June 2016). 
counterpart of the Children's Committee. Lastly, we make a number of recommendations on how to ensure easy access for adolescents to emergency contraception.

We conclude by stressing the plea of Dr Nafis Sadik on World Health Day: 298

We must do everything we can to prevent unwanted, unintended and high-risk pregnancies, including making family planning information and services universally available. The technologies and techniques needed are all well-known. Countries need only the will to act.

It goes without saying that without the political will to implement the recommendations we and others have made regarding the need to ensure adolescents' access to emergency contraceptives, unwanted, unintended and high-risk pregnancies will remain part of adolescents' lives.

298 Statement by $\mathrm{Dr}$ Nafis Sadik on World Health Day, 7 April 1999, http:// www.familycareintl.org/UserFiles/File/pdfs/FCI_SRH_Briefing\%20Cards.pdf (accessed 7 June 2016). 